University of Nebraska - Lincoln

DigitalCommons@University of Nebraska - Lincoln

\title{
Growth-Size Scaling Relationships of Woody Plant Species Differ from Predictions of the Metabolic Ecology Model
}

\author{
Sabrina E. Russo \\ University of Nebraska - Lincoln, srusso2@unl.edu \\ Susan K. Wiser \\ Landcare Research, Lincoln New Zealand \\ David A. Coomes \\ University of Cambridge, Cambridge, UK, dac18@cam.ac.uk
}

Follow this and additional works at: https://digitalcommons.unl.edu/bioscifacpub

Russo, Sabrina E.; Wiser, Susan K.; and Coomes, David A., "Growth-Size Scaling Relationships of Woody Plant Species Differ from Predictions of the Metabolic Ecology Model" (2007). Faculty Publications in the Biological Sciences. 263.

https://digitalcommons.unl.edu/bioscifacpub/263

This Article is brought to you for free and open access by the Papers in the Biological Sciences at DigitalCommons@University of Nebraska - Lincoln. It has been accepted for inclusion in Faculty Publications in the Biological Sciences by an authorized administrator of DigitalCommons@University of Nebraska - Lincoln. 


\title{
Growth-Size Scaling Relationships of Woody Plant Species Differ from Predictions of the Metabolic Ecology Model
}

\author{
Sabrina E. Russo, ${ }^{1}$ Susan K. Wiser, ${ }^{2}$ and David A. Coomes ${ }^{1,2}$ \\ ${ }^{1}$ Conservation and Community Ecology Group, Department of Plant Sciences, \\ University of Cambridge, Cambridge, U.K. \\ ${ }^{2}$ Landcare Research, Lincoln, New Zealand \\ Corresponding author - S. E. Russo, srusso2@unl.edu
}

\begin{abstract}
The Metabolic Ecology Model predicts that tree diameter $(D)$ growth $(d D / d t)$ scales with $D^{1 / 3}$. Using data on diameter growth and height-diameter relationships for 56 and 40 woody species, respectively, from forests throughout New Zealand, we tested one prediction and two assumptions of this model: (i) the exponent of the growth-diameter scaling relationship equals $1 / 3$ and is invariant among species and growth forms, (ii) small and large individuals are invariant in their exponents and (iii) tree height scales with $D^{2 / 3}$. We found virtually no support for any prediction or assumption: growth-diameter scaling exponents varied substantially among species and growth forms, correlated positively with species maximum height, and shifted significantly with increasing individual size. Tree height did not scale invariantly with diameter. Based on a quantitative test, violation of these assumptions alone could not explain the model's poor fit to our data, possibly reflecting multiple, unsound assumptions, as well as unaccounted-for variation that should be incorporated.
\end{abstract}

Keywords: allometric scaling theory, growth form, growth-diameter scaling, height-diameter scaling, maximum likelihood methods, metabolic model of ecology, New Zealand forests, tree diameter growth, tree maximum height

\section{Introduction}

It has been argued that there are no general laws in ecology that are comparable to those in physics, but that ecology has some widely observed trends (Lawton 1999; Clarke \& Fraser 2004). To this end, the past 10 years has seen the growth of macroecology and the Metabolic Ecology Model (Brown 1995; West et al. 1997; Brown et al. 2004b), which aim to quantify some of ecology's widely observed trends and provide mechanistic explanations for them. For plants, hypotheses from the Metabolic Ecology Model propose that all species share an optimal design of the vascular system (West et al. 1999), which affects whole-plant physiology, biomass partitioning, and population and community processes (Enquist et al. 1998; Enquist \& Niklas 2001, 2002; Coomes 2006).

A prediction of the Metabolic Ecology Model (see Background to the metabolic ecology model of tree growth) applied to trees is that stem diameter $(D)$ growth $(d D / d t)$ should scale with, $\beta D^{\alpha}$, where $\alpha=1 / 3$, and $\beta$ is a propor- tionality constant, or allometric coefficient (Enquist et al. 1999). According to this model, although species may differ in their allometric coefficients, their exponents $(\alpha)$ are invariant (Enquist 2003). The proponents of the Metabolic Ecology Model have repeatedly argued that scaling relationships should apply universally, with taxonomic and other sources of variation being subsumed in the coefficient (Enquist 2003; Gillooly et al. 2006), but other researchers have argued that patterns found at larger scales may not be observed at smaller ones (Tilman et al. 2004).

The theoretical value of the growth-diameter scaling exponent arises from at least four assumptions about the structure of plant vascular networks: it is volumefilling and fractal, its hydrodynamic resistance is minimized, petiole diameter does not vary with plant size, and it is constructed to resist elastic buckling of the tree due to gravity (Enquist et al. 1999, 2000; Coomes 2006). Resources such as light are also assumed to be equally available to all trees (Enquist et al. 1999, 2000; Coomes 2006). Furthermore, the value of the growth-diame- 
ter scaling exponent relies critically on the assumptions that tree mass $(M)$ scales with tree diameter as $D^{8 / 3}$ and that tree height $(H)$ scales as $D^{2 / 3}$ (see Background to the metabolic ecology model of tree growth). The applicability of these assumptions may vary across species, growth forms and environments, thereby generating variation in the observed exponent that would violate its predicted universal applicability.

Evaluations of the predicted scaling of tree growth with diameter have been relatively few. The model was supported by analyses in the paper in which it was originally proposed (Enquist et al. 1999), although sample sizes may not have been sufficient to test the hypothesis robustly (Muller-Landau et al. 2006a; Coomes \& Allen in press). Furthermore, tests in 10 tropical forest communities showed little evidence that $\alpha=1 / 3$ (Muller-Landau et al. 2006a). In that study, vertical variation in light in forests was proposed to influence the changing relationship between tree growth and diameter, such that as a tree grows into increasingly better light environments as it reaches the canopy, limitation of growth rate by competition for light declines (Muller-Landau et al. 2006a). Any such asymmetry in resource competition (Weiner 1990) could result in a growth-diameter scaling exponent that changes with size (Kerkhoff \& Enquist 2006; Coomes \& Allen in press). Changes in resource allocation with the onset of reproduction or in tissue density, particularly of wood, as trees age, are also likely to cause shifts in the growth-size relationship (Enquist 2002; Muller-Landau et al. 2006a). For these reasons, forest ecologists have favored diameter growth models that incorporate terms accounting for potential ontogenetic changes in growth rate, namely hump-shaped functions or functions with inflection points allowing declining growth rates as a tree matures (Zeide 1989; Monserud \& Sterba 1996; Weiner \& Thomas 2001). Both effects could lead to deviations from the predicted exponent, particularly for large trees, implying that the growth-diameter scaling exponent would approach zero as a tree increases in size. Moreover, tests of scaling relationships often do not account for taxonomic variation, as the generality of the Metabolic Ecology Model lies in its treatment of all individuals as identical, and hence its predicted exponents are for average responses (Clarke 2006; Muller-Landau et al. 2006a). However, tree demographic rates show substantial interspecific and intraspecific variation (Kobe 1996; Clark et al. 2003; Condit et al. 2006).

Here, we test several hypotheses and assumptions of the Metabolic Ecology Model applied to trees. First, we used diameter growth data from 119,360 individuals of 56 woody species collected over 36 years in forests throughout New Zealand to evaluate whether the exponent $(\alpha)$ of the growth-diameter scaling relationship equals $1 / 3$ and is invariant among species and growth forms, implying that interspecific and other life-history variation is accounted for in the coefficient $(\beta)$. Shrubs and small trees found in closed-canopy forest generally have more conservative growth strategies that allow them to survive their entire lives in the shade of canopy trees. Any deviations of the scaling exponent from $1 / 3$ that were related to growth form would indicate that asymmetric competition for light might be inadequately described by the Metabolic Ecology Model. Second, we evaluated whether small and large trees of a species are invariant in their exponents. If this were the case, then the assumption that there are no ontogenetic changes in resource allocation or access as trees age, or at least that such change is accounted for by the allometric coefficient, would be justifiable. Third, using data on tree height-diameter relationships for 40 New Zealand tree species, we tested whether the assumption that $H \propto$ $D^{\delta}$, where $\delta=2 / 3$, holds and is invariant across species. Fourth, we further hypothesized that the height-diameter scaling exponent $(\delta)$ would be negatively correlated with any deviations from the predicted growth-diameter scaling exponent ( $\alpha$; see Background to the metabolic ecology model of tree growth). Finally, a species' maximum height is an important trait related to allocation to diameter vs. height growth and photosynthetic capacity (Thomas \& Bazzaz 1999; Kohyama et al. 2003; Westoby \& Wright 2006). We therefore also tested whether these two scaling exponents were correlated with maximum height. By evaluating these assumptions and quantifying patterns of covariation between parameters of these scaling relationships and tree functional traits, we sought to identify where the theoretical challenges lay in improving the applicability of the Metabolic Ecology Model.

\section{Background to the Metabolic Ecology Model of Tree Growth}

The growth-diameter scaling relationship for trees is derived from a complex series of relationships and assumptions (West et al. 1997, 1999; Enquist et al. 1999, 2000; Enquist 2002; Makarieva et al. 2005; Chaui-Berlinck 2006; Coomes 2006), which we briefly summarized here. (1) The hydraulic resistance of conduits (vessels or tracheids) in the vascular system does not increase substantially with increasing length of the transport system. This is due to the way that conduits taper, which is dictated by the assumptions that the network of conduits branches fractally and is area-preserving. As a result, neither water delivery to leaves, nor the transpiration rate per unit leaf area, nor photosynthetic rate per unit leaf area, diminishes with tree size. (2) Consequently, whole-tree photosynthetic rate is proportional to total leaf area. (3) Total leaf area is assumed to be directly proportional to the basal area of the stem, a relation that arises from the assumption of area-preserv- 
ing branching. Hence, whole-tree photosynthetic rate scales with tree diameter $(D)$ squared. (4) Total biomass growth $(d M / d t)$ is directly proportional to total photosynthetic rate, and so also scales with $D^{2}$. (5) Tree height $(H)$ scales with diameter as, $H \propto D^{2 / 3}$ (McMahon \& Kronauer 1976), and $M$ scales with tree volume, $D^{2} H$; hence, $M \propto D^{8 / 3}$. (6) Substituting $D^{8 / 3}$ into $d M / d t \propto D^{2}$ yields, $d D / d t \propto D^{1 / 3}$. As an aside, these relationships also imply that $M \propto H^{4}$ (Makarieva et al. 2005).

The growth-diameter scaling relationship, $d D / d t \propto$ $D^{1 / 3}$, relies critically on the assumption that $H \propto D^{2 / 3}$. If tree height and diameter fail to scale according to this assumption, then this might result in deviations of the growth-diameter scaling exponent from $1 / 3$. Specifically, if $H \propto D^{\delta}$, then by the same logic as in steps (56) above, it follows that $M \propto D^{2+\delta}$ and $d D / d t \propto D^{(1-\delta)}$. Hence, a significant correlation between $\alpha_{\mathrm{j}}$ and $\left(1-\delta_{j}\right)$ would indicate that inappropriate assumptions about tree height growth with respect to diameter might be partly responsible for any deviations of $\alpha_{j}$ from the predicted 1/3, where $\delta_{j}$ and $\alpha_{j}$ are the growth-diameter and height-diameter scaling exponents for species $j$, respectively.

\section{Methods}

\section{Ecological setting and allometric data}

The forests of New Zealand are dominated by longlived evergreen and southern hemisphere, temperate woody taxa, but also contain representatives from largely tropical lineages, particularly in the warmer north (e.g. Litsea and Beilschmedia, Lauraceae), as well as some genera that are endemic to New Zealand (e.g. Coprosma, Rubiaceae). Woody species have varied growth forms, ranging from some of the world's largest canopy trees (e.g. Agathis australis, Podocarpaceae) to divaricating understory shrubs. In association with a diverse group of broad-leaved hardwoods, Nothofagus (Southern beech; Nothofagaceae) and conifer species (Podocarpaceae and Cuppressaceae) predominate in many forest types, with beeches tending to dominate mountainous regions and tall podocarps being more abundant in lowland forests (Wardle 1991).

Data on the change in tree diameter over time of woody plant species of New Zealand were extracted from the National Vegetation Survey (NVS) data bank (Wiser et al. 2001). Between 1969 and 2004 permanently marked $20 \times 20 \mathrm{~m}\left(400 \mathrm{~m}^{2}\right)$ plots were placed in a stratified random design along compass lines in watersheds throughout New Zealand. The origin of each line was located randomly along a stream channel, and plots were established at 200-m intervals upslope along each line until alpine grassland was reached. Within each plot, each woody stem $>30 \mathrm{~mm}$ in diameter at breast height (diameter) was tagged and identified to species and its diameter recorded to the nearest $1 \mathrm{~mm}$. Plots were recensused at varying intervals ranging from $c$. 2-28 years, with each plot being censused a maximum of four times from 1969 to 2004.

We selected data on trees that had been measured at least twice and grouped them into (i) stems of all size classes, (ii) stems of $30-200 \mathrm{~mm}$ and (iii) stems $\geq 200$ $\mathrm{mm}$ in diameter both with and without respect to species. For species-specific parameter estimates, we used data from species that had at least 100 stems in each of these groups, because previous analyses demonstrated this to be a threshold of statistical power below which confidence intervals on growth-diameter scaling parameters become excessively wide. This amounted to 120,842 individuals of 56, 51, and 14 species, respectively, collectively representing 20 families. We report the diameter size range in the data for each species, as this can potentially influence the scaling exponent (Table S1).

Data on tree diameter-height relationships were from the New Zealand Carbon Monitoring System (CMS; Coomes et al. 2002; Payton et al. 2004). Data were from trees 12 to $5320 \mathrm{~mm}$ in diameter from 377 marked 20 $\times 20 \mathrm{~m}\left(400 \mathrm{~m}^{2}\right)$ permanent plots in the CMS system. These plots are a systematic sample of forested areas of New Zealand. In each plot, diameter and height (using a Haglöf vertex hypsometer, Langsele, Sweden) were measured on trees that were non-randomly selected to obtain a broad-range of diameters and species.

Temperature data (see below) were mean annual temperatures from the Land Environments of New Zealand Geographic Information System database. Mean annual temperatures were derived directly from a spline surface fitted to data from 300 meteorological stations. The values used to fit the surface consisted of the mean of the 12 monthly averages for daily average temperature (Leathwick et al. 2002). The geo-referenced plot locations were used to extract mean annual temperature $(T)$ for each plot, which was applied to every tree in that plot.

We also collected data on the growth form and maximum height attained for each species from the literature (Wardle 1991; Poole \& Adams 1994; Wilson 1994) and the New Zealand Plants Databases (Landcare Research 2006; http://nzflora.landcareresearch.co.nz/ ). We categorized species broadly into three growth forms: (i) canopy trees (CT; 18 species) were species with maximum heights $>15 \mathrm{~m}$ that have a tree-like growth form and are found in closed-canopy forest, (ii) small trees (ST; 25 species) had maximum heights between 5 and $15 \mathrm{~m}$, may have a tree-like or branching growth form in one or more life stages, and may occur in closed canopy or more open forest habitats and (iii) shrubs (SH; 13 species) had maximum heights $<5 \mathrm{~m}$ and a branching growth form (Table S1). 


\section{Modeling approach}

Tree growth-diameter scaling

The instantaneous growth rate $(G)$ of a tree was modeled as a power function of its diameter $(D$; Equation 1 ; Enquist et al. 1999; Muller-Landau et al. 2006a).

$$
G(D)=\frac{d D}{d t}=\beta D^{\alpha}
$$

Note that while $\alpha$ is a dimensionless quantity, $\beta$ is not. Because in our study $D$ and time have units of $\mathrm{mm}$ and years, respectively, when $D=1, \beta$ is therefore the predicted growth rate in $\mathrm{mm}_{\text {year }}{ }^{-1}$ of a $1-\mathrm{mm}$ in diameter tree. Integrating this growth function gives

$$
D_{t}^{1-\alpha}=D_{0}^{1-\alpha}+\beta(1-\alpha) t
$$

where $D_{0}$ is a tree's diameter at time $t_{0}$ (the first time it was observed alive) and $D_{t}$ is its diameter at time $t$ (the last time it was observed alive; Muller-Landau et al. 2006a). Applying the relationship in Equation 2 to our data and accounting for individual variation, we obtain

$$
\left.D_{t i j}=D_{0 i j}^{1-\alpha_{j}}+\beta_{j}\left(1-\alpha_{j}\right) t_{i j}\right)^{\frac{1}{1-\alpha_{j}}}+\varepsilon_{i j}
$$

for tree $i$ of species $j$. We assumed that individual deviations from the predicted final diameter, $\varepsilon_{i j^{\prime}}$ were lognormally distributed and depended on the length of the intercensus interval $t_{i j}$, which varied among trees:

$$
\begin{aligned}
\varepsilon_{i j} & \sim \log N\left(\mu_{i j} ; \sigma_{i j}\right) \\
\mu_{i j} & =\log \left(E\left[D_{i j}\right]\right)-\frac{\sigma_{i j}^{2}}{2} \\
\sigma_{i j} & =s_{j} t_{i j}
\end{aligned}
$$

where $\mu_{i j}$ and $\sigma_{i j}$ are the location and scale parameters of the lognormal distribution, $E\left[D_{t i j}\right]$ is the predicted value of the final diameter of an individual tree, and $s_{j}$ is the time-independent standard deviation of the lognormal distribution. Thus, the error variance $\left(\sigma_{i j}{ }^{2}\right)$ is scaled with time. We also tested normal and gamma probability distributions for the model's error distribution, but found the lognormal distribution to have the highest likelihood for the greatest number of species.

The Metabolic Ecology Model predicts that temperature governs metabolism through its effects on rates of biochemical reactions, and so diameter growth rate should not only depend on tree size, but should increase with increasing temperature (Gillooly et al. 2001). We corrected growth rates to a standard temperature $\left(T_{0}\right.$ in $\left.\mathrm{K}\right)$ based on the universal temperature dependence of biological processes, $e^{E\left(T-T_{0}\right) /\left(k T T_{0}\right)}$, where $E$ is the activation energy of metabolic processes (c. 0.65 $\mathrm{eV}), k$ is the Boltzmann constant $\left(8.62 \times 10^{-5} \mathrm{eVK}^{-1}\right), T$ is observed temperature in K (Gillooly et al. 2001), and
$T_{0}$ is the mean temperature across all plots in the NVS data $(281.6 \mathrm{~K})$ :

$$
G(D, T)=\beta D^{\alpha} e^{\frac{E\left(T-T_{0}\right)}{k T T_{0}}}
$$

Thus, the temperature-standardized growth-diameter scaling model with a lognormal error distribution, as in Equation 4, is:

$$
D_{i j}=\left(D_{0 i j}^{1-\alpha_{j}}+\beta_{j}(1-\alpha) t_{i j} e^{\frac{E\left(T-T_{0}\right)}{k T T_{0}}}\right)^{\frac{1}{1-\alpha_{j}}}+\varepsilon_{i j}
$$

\section{Tree height-diameter scaling}

The height $(H)$ of a tree was modeled as a function of its diameter $(D)$ using a power function (Enquist et al. 2000):

$$
H(D)=\gamma D^{\delta}
$$

Because tree height growth often reaches an asymptote as a tree ages, we also fit an asymptotic function to the height-diameter relationship, the Monod equation (Equation 8):

$$
H(D)=H_{\max }\left(1-e^{\phi D^{\eta}}\right)
$$

where $H_{\max }$ is the maximum height. We assumed errors were lognormally distributed.

\section{Model fitting and evaluation}

We fit the growth-diameter scaling relationship without and with the temperature correction (Equations 3 and 6) to all stems, small stems, and large stems both without and with respect to species (i.e. single $\alpha, \beta$, and $s$ vs. species-specific $\alpha_{j}, \beta_{j}$, and $s_{j}$ parameters, respectively). When $\alpha$ and $\beta$ were fit simultaneously, different combinations of $\alpha$ and $\beta$ resulted in nearly identical likelihood values, indicating possible parameter tradeoffs between $\alpha$ and $\beta$ and reflecting considerable variability in the data. When $\alpha \geq 1$, Equation 3 is undefined. We therefore fixed $\alpha$ at a range of values $<0.99$ in increments of 0.01 , and for each of these values of $\alpha$, we fitted $\beta$ and $s$ by minimizing the negative log of the likelihood function (-LL). We decreased the lower end of the range of $\alpha$ until it was clear that the -LL reached a minimum. From these results, we took the maximum likelihood estimates (MLE) for $\alpha$ and $\beta$ to be the combination that had the lowest -LL. This model-fitting approach accords well with the idea that $\alpha$ is proposed to be invariant, and interspecific variation is accounted for in $\beta$ (Enquist \& Niklas 2002; Clarke 2006). We fit the heightdiameter scaling models (Equations 7 and 8) for each of 40 species with 20 or more stems.

We used the Nelder-Mead simplex search algorithm (Nelder \& Mead 1965), and varied initial parameter values to minimize the risk of finding only a local maximum likelihood. We compared the fits of growth-diameter scaling models without and with temperature standardization and of the three height-diameter scal- 
ing models using Akaike's Information Criterion (AIC = $-2 L L+2 k$, where $k$ is the number of fitted parameters; Hilborn \& Mangel 1997). We used the difference in AIC between the two models ( $\triangle \mathrm{AIC}$ ) to judge relative support, with lower values of AIC indicating more support. We considered $\triangle \mathrm{AIC}<2$ to indicate similar support, $\triangle \mathrm{AIC}=2-10$ to indicate moderate and $\triangle \mathrm{AIC}>10$ to indicate strong support, respectively, for the alternative models (Burnham \& Anderson 1998).

We report the MLEs for all parameters, except the error variance parameters, of the best-supported models, with two-unit asymptotic support intervals (SI; Edwards 1972; Hilborn \& Mangel 1997). Two-unit SIs for MLEs of parameters were estimated by fixing the standard deviation of the error distribution and either $\alpha$ or $\beta$ for the growth-diameter scaling model or either $\gamma$ or $\delta$ for the height-diameter scaling model at their respective MLEs and systematically varying the parameter for which SIs were being estimated on a grid to find the parameter values that were two likelihood units away from the MLE for that parameter. Estimates of allometric exponents were considered different from the predicted values $(\alpha=1 / 3$ and $\delta=2 / 3)$ if their SIs did not contain $1 / 3$ or $2 / 3$, respectively.

We examined variation in $\alpha_{j}, \beta_{j}$ and $\delta_{j}$ parameters with respect to both species' maximum height and growth form using Spearman's rank correlation and Kruskal-Wallis tests and used Spearman's rank correlation to quantify the relationship between $\alpha_{j}$ and $1-$ $\delta_{j}$ (Conover 2003; see Background to the metabolic ecology model of tree growth).

\section{Results}

\section{Overall growth-diameter scaling relationship}

Maximum likelihood estimates of $\alpha$ based on fits of the growth-diameter scaling relationship without temperature standardization (Equation 1) and without respect to species, were 0.50 (SI: 0.498-0.502) for all stems, 0.46 (SI: 0.458-0.462) for small stems and 0.06 (SI: 0.055$0.065)$ for large stems. The corresponding allometric coefficients were 0.075 (SI: $0.0745-0.0757$ ) for all stems, 0.089 (SI: 0.0892-0.0908) for small stems and 0.902 (SI: $0.875-0.931)$ for large stems. The scaling relationship fitted using data for all stems (without size class divisions) poorly predicted growth of larger trees because for trees greater than c. $20 \mathrm{~cm}$ in diameter, mean growth did not vary predictably with diameter, and the relationship was approximately flat (Figure 1).

After standardizing for temperature, MLEs for $\alpha$ shifted only slightly: 0.52 (SI: $0.518-0.522$ ) for all stems, 0.49 (SI: 0.488-0.492) for small stems and 0.03 (SI: 0.025 to -0.035$)$ for large stems. The corresponding allometric coefficients were 0.067 (SI: 0.0662-0.0673) for all stems, 0.077 (SI: 0.0763-0.0776) for small stems and 1.039

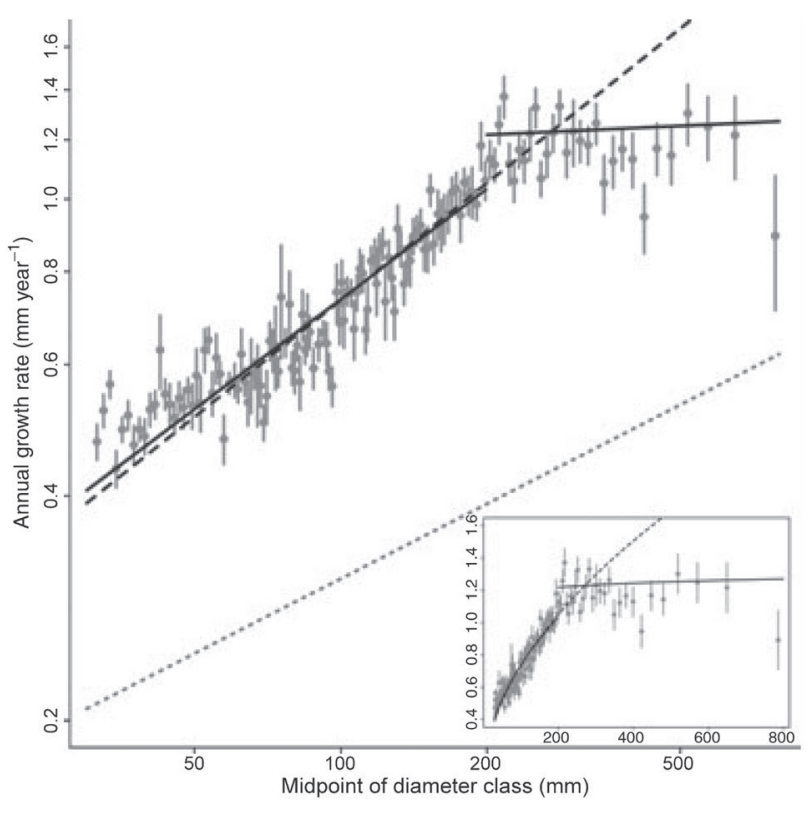

Figure 1. Annual tree diameter growth rate as a function of diameter for New Zealand trees. Points are mean values of observed growth rates within diameter classes, with standard error bars, plotted on a log-log scale. Diameter classes were based on $6 \%$ quantiles of the growth rate distribution and contained 230-1960 individuals. Growth rates (mm year-1) are the difference between two diameter measurements $(\mathrm{mm})$ divided by the time between them (years). Curves represent the temperature-standardized growth-diameter scaling relationship (Equation 6) fit to all stems (dashed line) and stems 3-20 cm and stems $\geq 20 \mathrm{~cm}$ in diameter (two solid lines) without respect to species. The grey dotted line shows the predicted scaling relationship ( $\alpha=1 / 3$ and $\beta$ fixed at the fitted value for all stems). The inset shows the same fitted curves and data on non-logged axes.

(SI: 1.0054-1.0727) for large stems. Thus, based on these SIs, all estimates of $\alpha$ (both with and without temperature standardization) were significantly different from the value of $1 / 3$ predicted by the Metabolic Ecology Model (Enquist et al. 1999). Based on AIC, the temperature-standardized model had a substantially better fit than the unstandardized model $(\triangle \mathrm{AIC}$ $=13650.2$ for all stems; $\triangle \mathrm{AIC}=9746.4$ for small stems; $\triangle \mathrm{AIC}=3829.2$ for large stems). Therefore, only results from the temperature-standardized model (Equation 6) will be presented.

\section{Species-specific variation in the growth-diameter scal- ing relationship}

Across all size classes, New Zealand tree species were highly variable in both their exponents $(\alpha)$ and coefficients $(\beta)$ of the temperature-standardized growthdiameter scaling relationship (Table S2). As a result, the functional diversity of predicted growth curves among 
species and growth forms was substantial (Figure 2). Species-specific MLEs for $\alpha$ were in the range of -1.61 to 0.99 based on all stems, -1.64 to 0.99 based on small stems, and -1.76 to 0.99 based on large stems (Table S2). MLEs of $\alpha$ differed from $1 / 3$ for most species and size classes (Table 1 and Table S2).

For CTs, $\alpha$ was more likely to be $>1 / 3$, based on all and small stems, whereas for CTs based on large stems and for STs and shrubs (all stems and small stems), $\alpha$ was frequently $<1 / 3$ (Table 1$)$. Both parameters also varied significantly among growth forms $(\alpha$ : Kruskal-Wallis $\chi^{2}=12.12$, d.f. $=2, P=0.002$; b: Kruskal-Wallis $\chi^{2}=$ 10.99 , d.f. $=2, P=0.004$ ) across all size classes (Figure 3). This was also true for $\alpha$ when data were grouped by size classes (small stems, $\alpha$ : Kruskal-Wallis $\chi^{2}=8.57$, d.f. $=$ $2, P=0.014)$, although for $\beta$, overall differences among growth forms for small stems were only close to being statistically significant ( $\beta$ : Kruskal-Wallis $\chi^{2}=5.79$, d.f. $=2, P=0.055)$. Our ability to test these relationships statistically using only trees $\geq 20 \mathrm{~cm}$ in diameter was reduced by limited sample size. Based on all stems, CTs had significantly higher parameter estimates for $\alpha$ than did both STs and shrubs $(P<0.001$ and $P=0.02$, respec- tively), which themselves did not differ significantly $(P>0.05)$. Estimates of $\beta$ based on all stems were significantly lower for canopy than for STs $(P<0.001)$, but there were no significant differences between either $\mathrm{CTs}$ and shrubs or STs and shrubs $(P>0.05)$. Similar patterns of variation among growth forms in $\alpha$ and $\beta$ held based on small stems (Figure 3).

For 10 of 11 CT species and two of three ST species with sufficient sample size for analysis, estimates of $\alpha$ were greater for small, relative to large stems, implying a stronger diameter dependence of growth for juvenile trees that have not yet reached the forest canopy. Hence, as growing trees approach the forest canopy, $\alpha$ shifts to smaller values, making growth rates less size-dependent (Table S2; Figures 1 and 3). The median of the $\alpha$ value for all species for fits based on all stems was near the predicted $1 / 3$ (Figure $3 \mathrm{~A}$ ). However, fits based on all stems generally did not predict growth of stems $>20$ $\mathrm{cm}$ very well (Figure 1), and there were strong shifts in $\alpha$ for small relative to large stems (Figure 3B-D). Thus, this tendency for the median $\alpha$ to be near $1 / 3$ is not very meaningful in terms of understanding growth of trees throughout their lifetime.
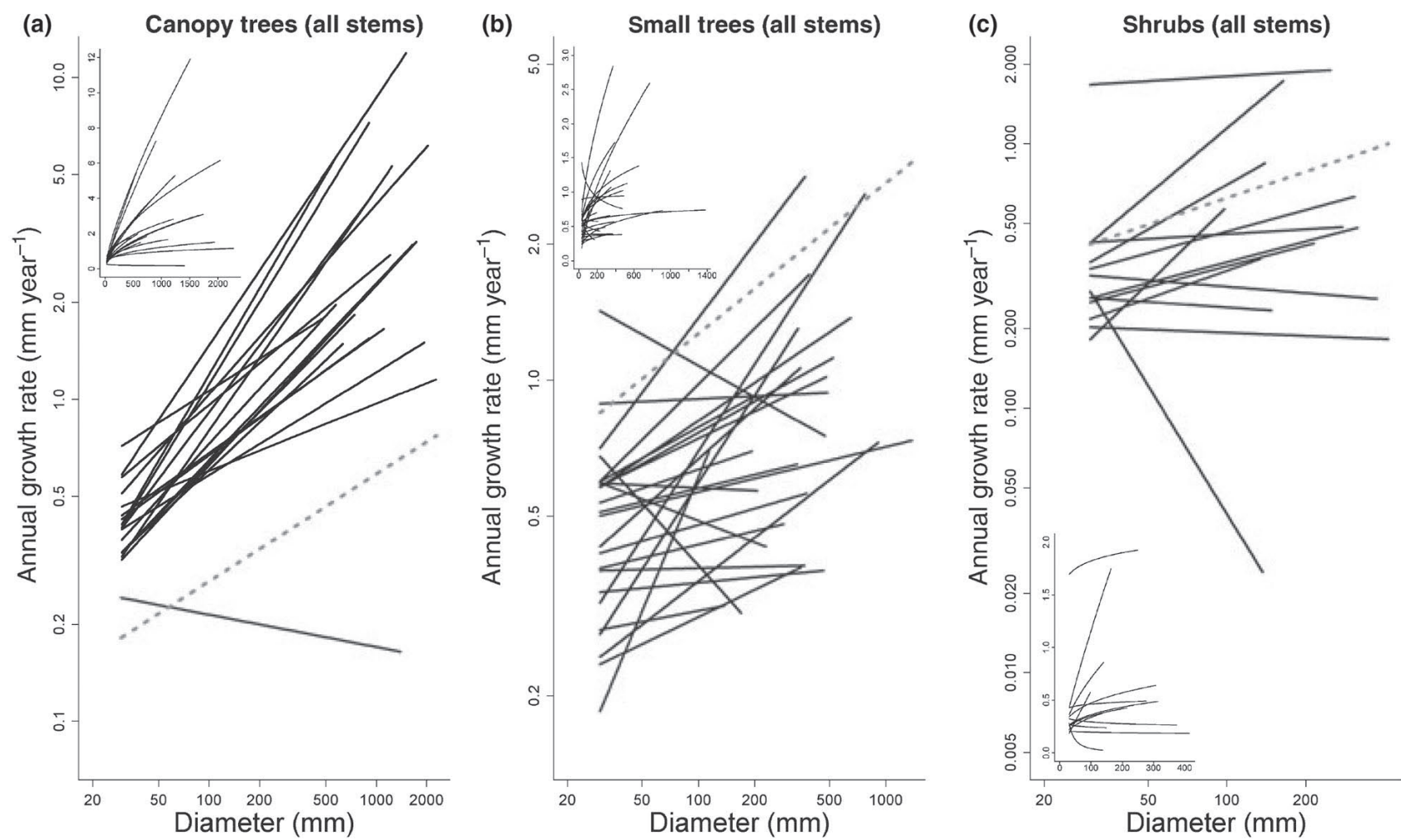

Figure 2. Plots of fitted relationships (solid black lines) for the temperature-standardized growth-diameter scaling relationship (Equation 6) for species in three growth forms: (a) canopy trees, (b) small trees and (c) shrubs, based on models fit using stems in all size classes. Note the change in scale of the y-axes and log-log axes. The dotted grey line shows the predicted scaling relationship ( $\alpha=1 / 3$, with $\beta$ fixed at the median of fitted values across species in that growth form). The curves span the range of diameters observed for each species. The insets show the same curves on non-logged axes. 
Table 1. Numbers of New Zealand tree species for which the maximum likelihood estimate of the exponent of the temperature-standardized growth-diameter scaling relationship ( $\alpha$; Equation 6) matched the predicted value from the Metabolic Ecology Model $(\alpha=1 / 3)$ or were either larger or smaller (counts of species are categorized according to growth form and size class)

\begin{tabular}{lrrrr}
\hline & & & & $\begin{array}{r}\alpha \text { not } \\
\text { different } \\
\text { from } 1 / 3\end{array}$ \\
\hline All stems & 18 & 14 & 2 & 2 \\
$\quad$ Canopy trees & 25 & 6 & 18 & 1 \\
$\quad$ Small trees & 13 & 3 & 9 & 1 \\
Shrubs & 56 & 23 & 29 & 4 \\
$\quad$ Total & & & & \\
Stems 3-20 cm & 14 & 9 & 5 & 0 \\
$\quad$ Canopy trees & 24 & 6 & 16 & 2 \\
Small trees & 13 & 3 & 10 & 0 \\
Shrubs & 51 & 18 & 31 & 2 \\
$\quad$ Total & & & & \\
Stems 20 cm & 11 & 2 & 9 & 0 \\
$\quad$ Canopy trees & 3 & 1 & 2 & 0 \\
Small trees & - & - & - & - \\
Shrubs & 14 & 3 & 11 & 0 \\
$\quad$ Total & & & & \\
\hline
\end{tabular}

A dash indicates that there were no species in this category with sufficient sample size to estimate parameters of the scaling relationship. The sum of values in the second, third and fourth columns equals the total number of species tested (column 1).

Based on all stems and small stems, species-specific estimates of $\alpha$ were positively correlated with species' maximum height (Spearman rank correlation: all stems, $\mathrm{Q}=0.42, P=0.001$; small stems, $\mathrm{Q}=0.41, P=0.003$; Figure $4 \mathrm{a}, \mathrm{b}$; both remained statistically significant when the data were limited to $\alpha>-1$ ), but not for large stems (Spearman rank correlation: $\mathrm{Q}=-0.04, P=0.88$; Figure 4c). These significant correlations were largely driven by differences among growth forms in maximum height combined with the significant variation in $\alpha$ among growth forms (Figure 3), as correlations between $\alpha$ and maximum height within growth forms for both small and large stems were all non-significant $(P>0.05$; Figure $4 \mathrm{a}-\mathrm{c})$. Predicted growth rates at $10 \mathrm{~cm}$ in diameter, based on species' MLEs for $\alpha$ and $\beta$ based on all stems, were significantly correlated with species' maximum heights, with a noticeable absence of slow-growing species with heights $>20 \mathrm{~m}$ (Pearson correlation: $\mathrm{Q}=0.33, P$ $=0.01$; Figure $4 \mathrm{~d}$ ).

\section{Species-specific variation in the height-diameter scal- ing relationship}

The power function (Equation 7) fit the tree heightdiameter relationship better than the Monod asymptotic function (Equation 8) for all but one species ( $\triangle \mathrm{AIC}>10$ for all species except Quintinia acutifolia, Grossulariaceae). Across species, $\triangle \mathrm{AIC}$ for both model comparisons ranged from -1.8 to 2434.3 , with an average of 138.5 . Therefore, only results from the height-diameter power function model (Equation 7) will be presented.

New Zealand tree species were variable in their height-diameter exponents $(\delta)$, averaging 0.45 (range: $0.02-0.72$ ). This range corresponds to that for North American tree species (Coomes \& Allen in press; mean, 0.40; range: $0.14-0.74)$. For all but two species, the exponent was different from the value of $2 / 3$ predicted from the Metabolic Ecology Model (Table 2). There was no significant variation among growth forms in the value of $\delta$ (Kruskal-Wallis $\chi^{2}=2.877$, d.f. $=2, P=0.237$ ), nor with maximum height (Spearman rank correlation: $\mathrm{Q}=$ $0.25, P=0.112$ ). In addition, there was no significant correlation among species between $\alpha$ of the growth-diameter scaling model and $(1-\delta$; Spearman rank correlation: $\varrho=-0.03, P=0.857)$.

\section{Discussion}

We found virtually no support in forests of New Zealand for a central prediction and two fundamental assumptions of the Metabolic Ecology Model that: the relationship between tree growth and diameter can be described by a power function with an invariant scaling exponent (a) equal to 1/3; growth-diameter scaling is equivalent for small and large trees; and the relationship between tree height and diameter can be described by a power function with a scaling exponent $(\alpha)$ equal to $2 / 3$. Furthermore, we found that the systematic violation of the assumption that $H \propto D^{2 / 3}$ was not solely responsible for the deviations of $\alpha$ from the predicted $1 / 3$ in the growth-diameter scaling relationship.

Varying arguments have been made as to whether or not scaling relationships apply at less than global scales, i.e. at scales of analysis that do not encompass the largest possible extent of body sizes or phylogenetic variation (Enquist \& Niklas 2001, 2002; Brown et al. 2004a,b). Our data, although not global in either respect, span the geographic extent of New Zealand and include almost all possible sizes of these woody species, and hence represent a significant proportion of the size and phylogenetic domains of South Temperate tree-dominated communities. It has also been argued that implicit assumptions of the Metabolic Ecology Model are that interspecific and intraspecific scaling should be identical because the same physical principles underpin both and that interspecific adjustment of metabolic scaling relationships is accomplished through the allometric coefficient. Nonetheless, even at this large geographic scale, indeed, at all scales of our analysis, whether or not we accounted for species, growth form or size, our results failed to substantiate either this prediction or these assumptions from the Metabolic Ecology Model. 


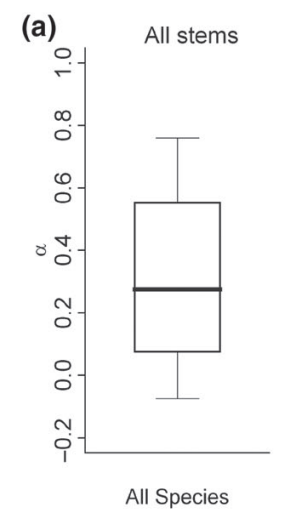

(e)

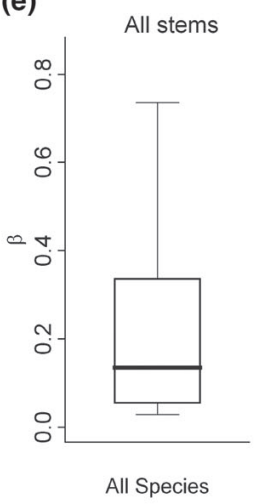

(b)

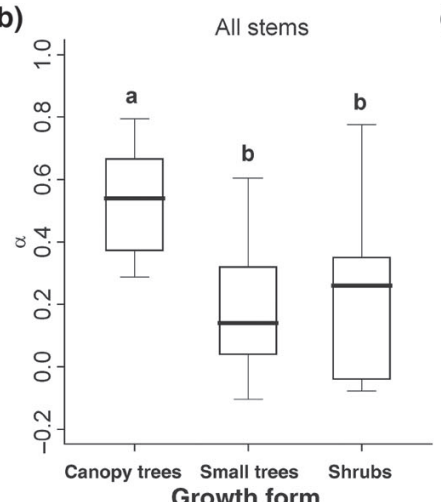

(f)

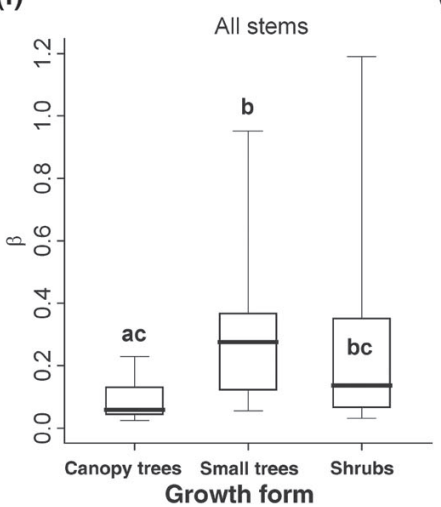

(c)

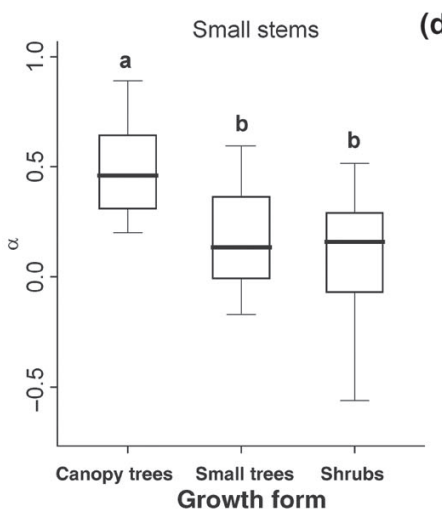

(g)

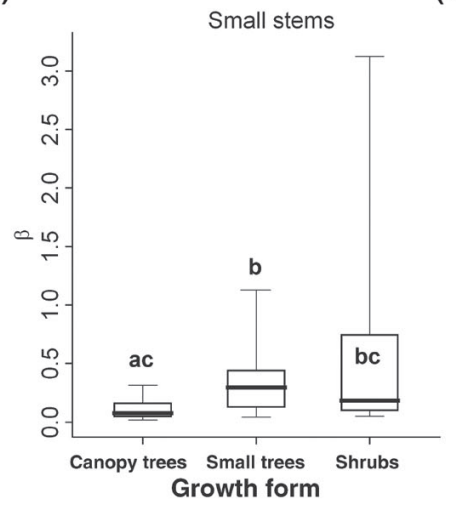

(d)

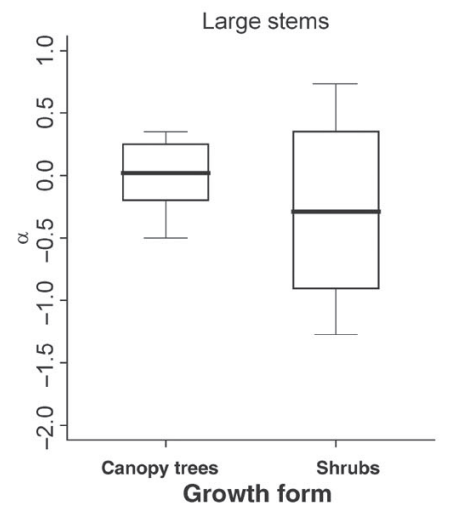

(h)

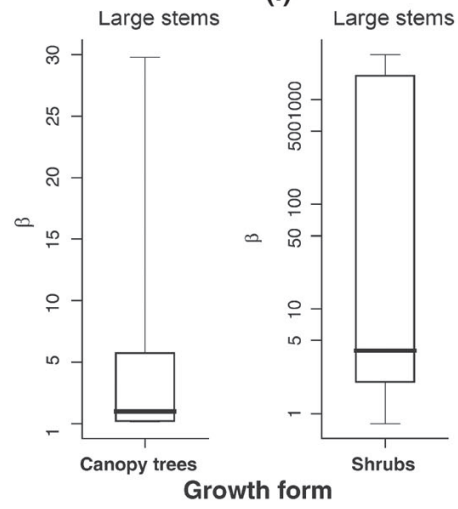

Figure 3. Variation among New Zealand tree species in three growth forms and two size classes in the exponent $(\alpha)$ and coefficient $(\beta)$ of the temperature-standardized growth-diameter scaling relationship (Equation 6). Note that dimensions for $\beta$ are mm year${ }^{1}$. The central bar in the boxplot indicates the median, the ends of the boxes indicate the interquartile range, and the whiskers indicate the 10th and 90th quantiles. Parameter estimates are based on data from all stems (a, b, e and f), small stems (c and g) and large stems ( $\mathrm{d}, \mathrm{h}$ and i) for $\alpha(\mathrm{a}-\mathrm{d})$ and $\beta(\mathrm{e}-\mathrm{i})$. In (a and $\mathrm{e})$, parameter variation across all species (and all growth forms) is shown. Differences among growth forms were tested using pairwise Wilcoxon signed rank tests with a Bonferonni correction (experiment-wise $\alpha=0.025$ ).

\section{Variation in growth-diameter scaling reflects inappro- priate model assumptions}

Our analyses demonstrated significant variation in the growth-diameter and height-diameter scaling exponents because of taxonomy, growth form and individual size. Such variation has long been recognized in forest ecology, particularly in terms of predicting successional dynamics and distributions along environmental gradients (Bazzaz 1979; King 1991; Kobe 1996). Variation in the allometric coefficient could not, however, account for all the variation among species in these scaling relationships, as is asserted by the Metabolic Ecology Model.

Most tree species tested showed a strong shift in both parameters of the growth-diameter scaling relationship from small to large size, such that growth of larger individuals became less size-dependent (lower $\alpha$ ). In addition, shrubs and smaller tree species, which tend to have more constant light environments from juvenile to adult stages, showed less size dependence of growth relative to CT species. Similarly, size dependence of growth was positively correlated with species' maxi- mum height, although this was largely due to variation among growth forms. A caveat is that diameter may be a poor measure of growth in size for shrubs, which can be multi-stemmed.

If unsound assumptions in the Metabolic Ecology Model about the scaling of tree height with diameter were largely responsible for the observed deviations from $1 / 3$ of the growth-diameter scaling exponents, then we would expect a to be correlated with $(1-\delta)$, as reasoned in Background to the metabolic ecology model of tree growth. However, there was no significant correlation. The fact that species' height-diameter exponents deviated so dramatically from the predicted $2 / 3$ suggests that the assumption, $H \propto D^{2 / 3}$, is indeed invalid, as found elsewhere (Zhang 1997; Niklas \& Spatz 2004). Nevertheless, this violation alone did not explain the poor fit of our data to the growth-diameter scaling prediction, and it is likely that other fundamental assumptions of the Metabolic Ecology Model also need re-appraisal.

Contrary to assumptions of the Metabolic Ecology Model, access to and allocation of resources changes ontogenetically. Clearly, access to light increases with tree 

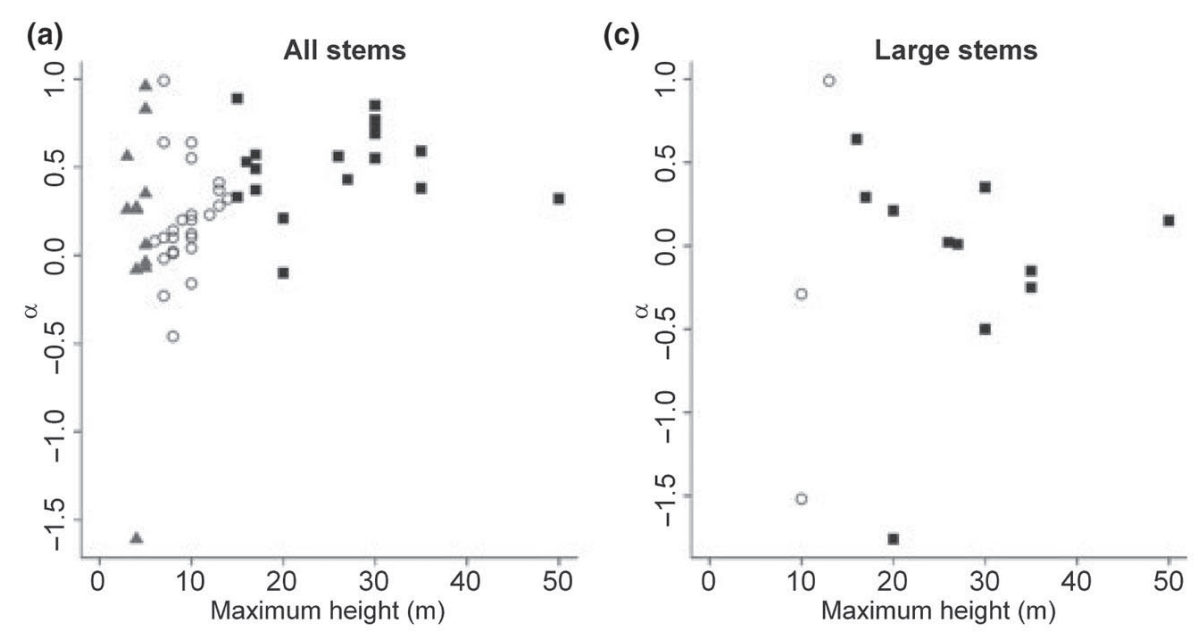

Figure 4. Covariation of the exponent $(\alpha)$ of the growth-diameter scaling relationship $G(D)=\beta D^{\alpha}(\mathrm{a}-\mathrm{c})$ and predicted growth at $100 \mathrm{~mm}$ diameter $(D=100)$, based on fitted temperature-standardized growth-diameter scaling relationships (Equation 6), (d) with maximum height for New Zealand tree species in three growth forms. Each point represents one species' parameter estimates using fits based on data for all stems (a and d), small (b) and large stems (c). Symbols represent growth forms: black squares, canopy trees; open circles, small trees; gray triangles, shrubs.
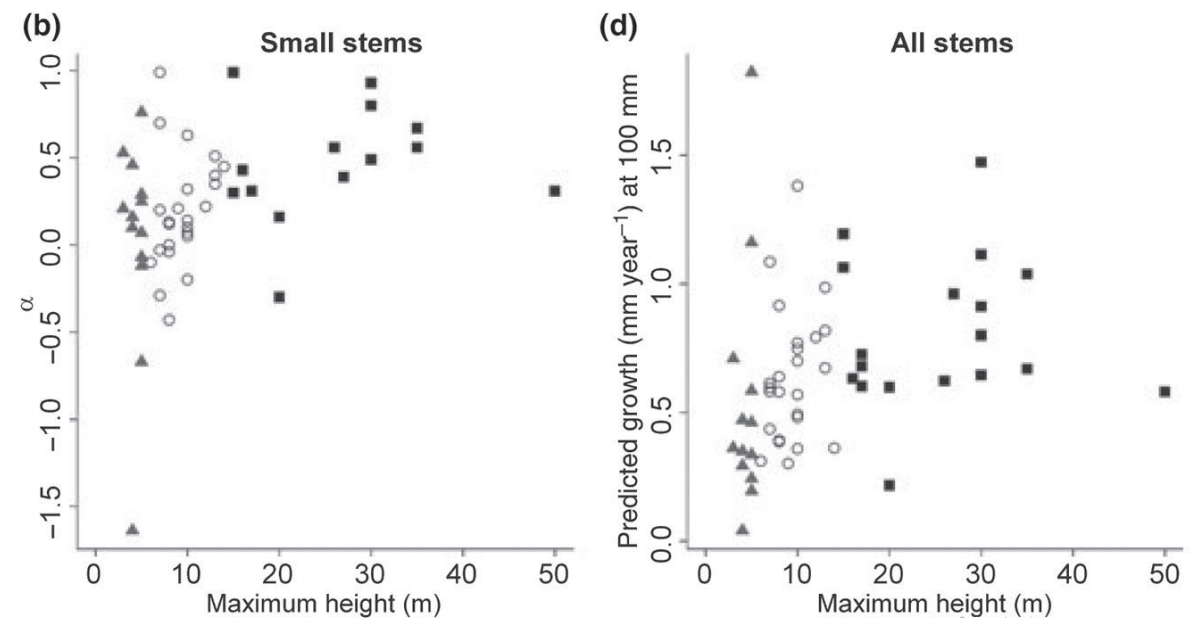

Table 2. Numbers of New Zealand tree species for which the maximum likelihood estimate of the exponent of the diameter-height scaling relationship ( $\delta$; Equation 7 ) matched the predicted value from the Metabolic Ecology Model $(\delta=2 / 3)$ or were either larger or smaller (counts of species are categorized according to growth form and size class)

\begin{tabular}{lrrrr}
\hline & Total tested & $\delta>2 / 3$ & $\delta<2 / 3$ & $\begin{array}{r}\delta \text { not } \\
\text { different } \\
\text { from 2/3 }\end{array}$ \\
\hline Canopy trees & 18 & 0 & 17 & 1 \\
Small trees & 5 & 1 & 4 & 0 \\
Shrubs & 17 & 0 & 16 & 1 \\
Total & 40 & 1 & 38 & 2 \\
\hline
\end{tabular}

size (Wyckoff \& Clark 2005; Sheil et al. 2006), as light varies on a nearly monotonic vertical gradient (Canham et al. 1990). How size influences access to belowground resources such as mineral nutrients and water remains unresolved, but could be analogous to the case with light (Schwinning \& Weiner 1998). Whether there is any such consistent vertical or horizontal gradient in edaphic resources and how root growth and competition vary with size are, however, not well understood and may vary for different types of edaphic resources (Schwinning \& Weiner 1998; Coomes \& Grubb 2000), as well as for associations with symbionts that can facilitate nutrient uptake (Kiers et al. 2000). In New Zealand's forests, members of a dominant genus, Nothofagus, are all ectomycorrhizal (Wardle 1991), and tree growth is known to depend strongly on nutrient availability (Davis et al. 2004; Platt et al. 2004). Thus far, available evidence points to asymmetric competition for all resources being more influential for small individuals (Coomes \& Allen in press), making diameter dependence of growth stronger for them. The poor support for metabolic growth-size scaling predictions for trees that we found accords with recent direct tests (Muller-Landau et al. 2006a; Coomes \& Allen in press), as well as indirect tests from forestry. The latter have generally found that flexible models of tree growth allowing for an asymmetric, hump-shaped curve fit better than less complex ones, primarily because they can account for ontogenic shifts affecting growth, albeit phenomenologically (Zeide 1989; Monserud \& Sterba 1996; Uriarte et al. 2004). 
Shifts in the growth-diameter scaling exponent with size may also be due to violations of some assumptions of the branching models fundamental to the Metabolic Ecology Model, as found for the scaling of respiration with plant mass (Reich et al. 2006; Enquist et al. 2007). For example, variation in the growth-size scaling relationship with individual size may also be due to dramatic ontogenetic shifts in growth-related traits, as occurs in heteroblasty. Several New Zealand woody species, such as Dacrydium cupressinum and Podocarpus spp. (Podocarpaceae), Libocedrus bidwillii (Cupressaceae), Pseudopanax spp. (Araliaceae) and Elaeocarpus spp. (Elaeocarpaceae) have large shifts in crown allometry and leaf morphology (Dansereau 1964; Wardle 1991). For conifers, needle-like juvenile foliage transforms into scale-like adult foliage, with consequences for carbon uptake (Whitehead et al. 2004). Whatever their evolutionary origin, such shifts in crown allometry and leaf size may nullify the assumptions of the Metabolic Ecology Model that the vascular network is volume-filling and that petiole dimensions are fixed through ontogeny, and may be partly responsible for the deviations we found here.

Beyond these possibilities, the assumption in the Metabolic Ecology Model that a plant's biomass growth rate scales directly with its gross photosynthetic rate (Enquist et al. 1999) may not be true, even on average, given the functional diversity of plant growth strategies. A tree species' inherent growth rate is in part the outcome of fundamental evolutionary trade-offs in resource allocation, given its environment, that are partly related to fast vs. slow rates of living and to the redirection of resources that occurs with the onset of reproduction (Poorter \& Garnier 1999; Reich et al. 2003). Such trade-offs involve spectra of adaptations that promote fast growth (e.g. responsive photosynthetic machinery, lighter wood, rapid height growth or reduced defences against herbivory) vs. those that promote survival, but may lead to slower growth (e.g. thicker, tougher tissues or investment in lateral growth and defence against herbivory; Grime 1977; Kohyama 1987; Loehle 1988; Thomas 1995; Reich et al. 2003; Poorter et al. 2005; King et al. 2006; Sterck et al. 2006; Westoby \& Wright 2006). To the extent that such tradeoffs influence growth scaling relationships, they may be in part responsible for any deviations from the predicted $\alpha$ value of $1 / 3$. In this respect, a model that integrates known covariation with respect to broad functional trait spectra might be more generally applicable, while avoiding idiosyncrasy.

\section{Conclusions}

One of the most attractive features of metabolic ecology is its prediction of allometric scaling relationships based on simple mechanistic models of the scaling of resource distribution networks within organisms and the temperature dependence of biological processes, although the debates concerning their statistical and biological validity continue (Kozlowski \& Konarzewski 2004; Nee et al. 2005; Clarke 2006; Gillooly et al. 2006). Some studies show support, though mixed, for more fundamental predictions from these mechanistic models, including the scaling relationships within tree vascular networks (Meinzer et al. 2005; Anfodillo et al. 2006; Coomes et al. 2006). It is, however, clear from our analyses and other recent work that these mechanistic models, although an advance, are still inadequate for trees, as their more derived predictions have rarely been upheld (Coomes et al. 2003; Li et al. 2005; Muller-Landau et al. 2006a, b).

Here, we found that at least two fundamental assumptions of this model lack support and that multiple, interacting unsound assumptions may be responsible for the poor fit of the model to these New Zealand data. The challenge is now to improve the predictive power of the Metabolic Ecology Model by continuing systematic tests of its assumptions with the goal of uncovering dominant sources of unaccounted-for variation that should be incorporated into the model, while maintaining its simplicity. Our work suggests that a promising place to start is by integrating a more mechanistic description of the fundamental evolutionary trade-offs among functional trait spectra and ontogenetic change that influence growth rates.

Acknowledgments - We are grateful to the New Zealand Forestry Service and Landcare Research for establishing and maintaining the New Zealand Vegetation Survey and Carbon Monitoring System plot network and for use of this database for our study. This research was supported by a grant from the U.K. National Environmental Research Council and the New Zealand Foundation for Research, Science, and Technology (contract 9X0502). S.E.R. thanks Charlie Canham and Maria Uriarte for hosting a course on likelihood methods at the Institute of Ecosystem Studies in New York, U.S.A., and for helpful discussions of ecological modeling approaches. We thank Richard Duncan for comments on an earlier version of this manuscript and Hamish Maule for tireless help in preparing the data set for use.

\section{References}

Anfodillo, T., V. Carraro, M. Carrer, C. Fior, and S. Rossi (2006). Convergent tapering of xylem conduits in different woody species. New Phytol. 169: 279-290.

Bazzaz, F.A. (1979). The physiological ecology of plant succession. Ann. Rev. Ecol. Syst. 10: 351-371. 
Brown, J.H. (1995). Macroecology. University of Chicago Press, Chicago.

Brown, J.H., J.F. Gillooly, A.P. Allen, V.M. Savage, and G.B. West (2004a). Response to forum commentary on "Toward a metabolic theory of ecology." Ecology 85: $1,818-1,821$.

Brown, J.H., J.F. Gillooly, A.P. Allen, V.M. Savage, and G.B. West (2004b). Toward a metabolic theory of ecology. Ecology 85: 1,771-1,789.

Burnham, K.P. and D.R. Anderson (1998). Model Selection and Inference: A Practical Information-theoretic Approach. Springer, New York.

Canham, C.D., J.S. Denslow, W.J. Platt, J.R. Runkle, T.A. Spies, and P.S. White (1990). Light regimes beneath closed canopies and tree-fall gaps in temperate and tropical forests. Can. J. For. Res. 20: 620-631.

Chaui-Berlinck, J.G. (2006). A critical understanding of the fractal model of metabolic scaling. J. Exp. Biol. 209: 3,045-3,054.

Clark, J.S., J. Mohan, M. Dietze, and I. Ibanez (2003). Coexistence: how to identify trophic trade-offs. Ecology 84: 17-31.

Clarke, A. (2006). Temperature and the metabolic theory of ecology. Func. Ecol. 20: 405-412.

Clarke, A. and K.P.P. Fraser (2004). Why does metabolism scale with temperature? Func. Ecol. 18: 243-251.

Condit, R., P. Ashton, S. Bunyavejchewin, H.S. Dattaraja, S. Davies, S. Esufali, et al. (2006). Importance of demographic niches to tree diversity. Science 313: 98-101.

Conover, W.J. (2003). Practical Nonparametric Statistcs, 3rd ed. Wiley, New York.

Coomes, D.A. (2006). Challenges to the generality of WBE theory. TREE 21: 593-596.

Coomes, D.A. and R.B. Allen (in press). Effects of size, competition and altitude on tree growth. J. Ecol.

Coomes, D.A. and P.J. Grubb (2000). Impacts of root competition in forests and woodlands: a theoretical framework and review of experiments. Ecol. Monogr. 70: 171-207.

Coomes, D.A., R.B. Allen, N.A. Scott, C. Goulding, and P. Beets (2002). Designing systems to monitor carbon stocks in forests and shrublands. For. Ecol. Manage. 164: 89-108.

Coomes, D.A., R.P. Duncan, R.B. Allen and J. Truscott (2003). Disturbances prevent stem size-density distributions in natural forests from following scaling relationships. Ecol. Lett. 6: 980-989.

Coomes, D.A., K.L. Jenkins, and L.E.S. Cole (2006). Scaling of tree vascular transport systems along gradients of nutrient supply and altitude. Biol. Lett.-UK 3: 86-89.

Dansereau, P. (1964). Six problems of New Zealand vegetation. B. Torrey Bot. Club 91: 114-140.

Davis, M.R., R.B. Allen, and P.W. Clinton (2004). The influence of $\mathrm{N}$ addition on nutrient content, leaf carbon iso- tope ratio, and productivity in a Nothofagus forest during stand development. Can. J. For. Res. 34: 2,037-2,048.

Edwards, A.W.F. (1972). Likelihood, 1st ed. Cambridge University Press, Cambridge, U.K.

Enquist, B.J. (2002). Universal scaling in tree and vascular plant allometry: toward a general quantitative theory linking plant form and function from cells to ecosystems. Tree Physiol. 22: 1,045-1,064.

Enquist, B.J. (2003). Cope's Rule and the evolution of longdistance transport in vascular plants: allometric scaling, biomass partitioning, and optimization. Plant Cell Environ. 26: 151-161.

Enquist, B.J. and K.J. Niklas (2001). Invariant scaling relations across tree-dominated communities. Nature 410: 655-660.

Enquist, B.J. and K.J. Niklas (2002). Global allocation rules for patterns of biomass partitioning in seed plants. Science 295: 1,517-1,520.

Enquist, B.J., J.H. Brown, and G.B. West (1998). Allometric scaling of plant energetics and population density. $\mathrm{Na}-$ ture 395: 163-165.

Enquist, B.J., G.B. West, E.L. Charnov, and J.H. Brown (1999). Allometric scaling of production and life-history variation in vascular plants. Nature 401: 907-911.

Enquist, B.J., G.B. West, and J.H. Brown (2000). Quarterpower allometric scaling in vascular plants: functional basis and ecological consequences. In: Scaling in Biology (eds. J.H. Brown and G.B. West). Oxford University Press, New York, pp. 167-198.

Enquist, B.J., A.P.J.H.B. Allen, J.F. Gillooly, A.J. Kerkhoff, K.J. Niklas, C.A. Price, et al. (2007). Does the exception prove the rule? Nature 445: E9-E10.

Gillooly, J.F., J.H. Brown, G.B. West, V.M. Savage, and E.L. Charnov (2001). Effects of size and temperature on metabolic rate. Science 293: 2,248-2,251.

Gillooly, J.F., A.P. Allen, V.M. Savage, E.L. Charnov, G.B. West, and J.H. Brown (2006). Response to Clarke and Fraser: effects of temperature on metabolic rate. Func. Ecol. 20: 400-404.

Grime, J.P. (1977). Evidence for the existence of three primary strategies in plants and its relevance to ecological and evolutionary biology. Am. Nat. 111: 1,169-1,194.

Hilborn, R. and M. Mangel (1997). The Ecological Detective. Princeton University Press, Princeton, N.J.

Kerkhoff, A.J. and B.J. Enquist (2006). Ecosystem allometry: the scaling of nutrient stocks and primary productivity across plant communities. Ecol. Lett. 9: 419-427.

Kiers, E.T., C.E. Lovelock, E.L. Krueger, and E.A. Herre (2000). Differential effects of tropical arbuscular mycorrhizal fungal inocula on root colonization and tree seedling growth: implications for tropical forest diversity. Ecol. Lett. 3: 106-113.

King, D.A. (1991). Correlations between biomass allocation, relative growth rate and light environment in tropical forest saplings. Func. Ecol. 5: 485-492. 
King, D.A., S.J. Davies, S. Tan, and N.S.M. Noor (2006). The role of wood density and stem support costs in the growth and mortality of tropical trees. J. Ecol. 94: 670-680.

Kobe, R.K. (1996). Intraspecific variation in sapling mortality and growth predicts geographic variation in forest composition. Ecol. Monogr. 66: 181-201.

Kohyama, T. (1987). Significance of architecture and allometry in saplings. Func. Ecol. 1: 399-404.

Kohyama, T., E. Suzuki, T. Partomihardjo, T. Yamada, and T. Kubo (2003). Tree species differentiation in growth, recruitment and allometry in relation to maximum height in a Bornean mixed dipterocarp forest. J. Ecol. 91: 797-806.

Kozlowski, J. and M. Konarzewski (2004). Is West, Brown and Enquist's model of allometric scaling mathematically correct and biologically relevant? Func. Ecol. 18: 283-289.

Lawton, J.H. (1999). Are there general laws in ecology? OIKOS 84: 177-192.

Leathwick, J., F. Morgan, G. Wilson, D. Rutledge, M. McLeod, and K. Johnston (2002). Land Environments of New Zealand: Technical Guide. Landcare New Zealand, Hamilton, New Zealand.

Li, H.-T., X.-G. Han, and J.G. Wu (2005). Lack of evidence for $3 / 4$ scaling of metabolism in terrestrial plants. J. Integr. Plant Biol. 47: 1,173-1,183.

Loehle, C. (1988). Tree life history strategies: the role of defenses. Can. J. For. Res. 18: 209-222.

Makarieva, A.M., V.G. Gorshkov, and B.-L. Li (2005). Revising the distributive networks models of West, Brown and Enquist (1997) and Banavar, Maritan and Rinaldo (1999): metabolic inequity of living tissues provides cluse for the observed allometric scaling rules. J. Theor. Biol. 237: 291-301.

McMahon, T.A. and R.E. Kronauer (1976). Tree structures: deducing the principle of mechanical design. J. Theor. Biol. 59: 443-466.

Meinzer, F.C., B.J. Bond, J.M. Warren, and D.R. Woodruff (2005). Does water transport scale universally with tree size? Func. Ecol. 19: 558-565.

Monserud, R.A. and H. Sterba (1996). A basal area increment model for individual trees growing in even-and uneven-aged forest stands in Austria. For. Ecol. Manage. 80: 57-80.

Muller-Landau, H.C., R.S. Condit, J. Chave, S.C. Thomas, S.A. Bohlman, S. Bunyavejchewin, et al. (2006a). Testing metabolic ecology theory for allometric scaling of tree size, growth and mortality in tropical forests. Ecol. Lett. 9: 575-588.

Muller-Landau, H.C., R.S. Condit, K.E. Harms, C.O. Marks, S.C. Thomas, S. Bunyavejchewin, et al. (2006b). Comparing tropical forest tree size distributions with the predictions of metabolic ecology and equilibrium models. Ecol. Lett. 9: 589-602.
Nee, S., N. Colegrave, S.A. West, A. Grafen (2005). The illusion of invariant quantities in life histories. Science 309: $1,236-1,239$.

Nelder, J.A. and R. Mead (1965). A simplex algorithm for function minimization. Comput. J. 7: 308-313.

Niklas, K. and H.-C. Spatz (2004). Growth and hydraulic (not mechanical) constraints govern the scaling of tree height and mass. Proceedings of the National Academy of Sciences 101: 15,661-15,663.

Payton, I.J., C.L. Newell, and P.N. Beets (2004). New Zealand Carbon Monitoring System Indigenous Forest and Shrubland Data Collection Manual. Caxton Press, Christchurch, New Zealand, 68 pp.

Platt, K.H., R.B. Allen, D.A. Coomes, and S.K. Wiser (2004). Mountain beech seedling responses to removal of below-ground competition and fertiliser addition. New Zealand J. Ecol. 28: 289-293.

Poole, A.L. and N.M. Adams (1994). Trees and Shrubs of New Zealand. Manaaki Whenua Press, Lincoln, New Zealand.

Poorter, H. and E. Garnier (1999). Ecological significance of inherent variation in relative growth rate and its components. In: Handbook of Functional Plant Ecology (eds. F.I. Pugnaire and F. Vallardes). Dekker, New York, pp. 82-120.

Poorter, L., F. Bongers, F.J. Sterck, and H. Woll (2005). Architecture of 53 rain forest tree species differing in adult stature and shade tolerance. Ecology 84: 602-608.

Reich, P.B., I.J. Wright, J. Cavender-Bares, J.M. Craine, J. Oleksyn, M. Westoby, et al. (2003). The evolution of plant functional variation: traits, spectra, and strategies. Int. J. Plant Sci. 164: S143-S164.

Reich, P.B., M.G. Tjoelker, J.L. Machado, and J. Oleksyn (2006). Universal scaling of respiratory metabolism, size and nitrogen in plants. Nature 439: 457-461.

Schwinning, S. and J. Weiner (1998). Mechanisms determining the degree of size asymmetry in competition among plants. Oecologia V113: 447-455.

Sheil, D., A. Salim, J. Chave, J. Vanclay, and W.D. Hawthorne (2006). Illumination-size relationships of 109 coexisting tropical forest tree species. J. Ecol. 94: 494-507.

Sterck, F.J., L. Poorter, and F. Schieving (2006). Leaf traits determine the growth-survival trade-off across rain forest tree species. Am. Nat. 167: 758-765.

Thomas, S.C. (1995). Asymptotic height as a predictor of growth and allometric characteristics in Malaysian rain forest trees. Am. J. Bot. 83: 556-566.

Thomas, S.C. and F.A. Bazzaz (1999). Asymptotic height as a predictor of photosynthetic characteristics in Malaysian rainforest trees. Ecology 80: 1,607-1,622.

Tilman, D., J. HilleRisLambers, S. Harpole, R. Dybzinski, J. Fargione, C. Clark, et al. (2004). Does metabolic theory apply to community ecology? It's a matter of scale. Ecology 85: 1,797-1,799. 
Uriarte, M., C.D. Canham, J. Thompson, and J.K. Zimmerman (2004). A neighborhood analysis of tree growth and survival in a hurricane-driven tropical forest. Ecol. Monogr. 74: 591-614.

Wardle, P. (1991). Vegetation of New Zealand. Cambridge University Press, Cambridge, U.K.

Weiner, J. (1990). Asymmetric competition in plant populations. TREE 5: 360-364.

Weiner, J. and S.C. Thomas (2001). The nature of tree growth and the 'age-related decline in forest productivity.' OIKOS 94: 374-376.

West, G.B., J.H. Brown, and B.J. Enquist (1997). A general model for the origin of allometric scaling laws in biology. Science 276: 122-126.

West, G.B., J.H. Brown, and B.J. Enquist (1999). A general model for the structure and allometry of plant vascular systems. Nature 400: 664-667.

Westoby, M. and I.J. Wright (2006). Land-plant ecology on the basis of functional traits. TREE 21: 261-268.

Whitehead, D., A.S. Walcroft, K.L. Griffin, D.T. Tissue, M.H. Turnbull, V. Engel, et al. (2004). Scaling carbon uptake from leaves to canopies: insights from two forests with contrasting properties. In: Forests at the LandAtmosphere Interface (eds. J. Mencuccini, J. Grace, J. Moncrieff, and K.G. McNaughton). CABI International, Wallingford, U.K., pp. 231-254.

Wilson, H.D. (1994). Field Guide: Stewart Island Plants. Manuka Press, Christchurch, New Zealand.

Wiser, S.K., P.J. Bellingham, and L.E. Burrows (2001). Managing biodiversity information: development of New Zealand's National Vegetation Survey databank. New Zealand J. Ecol. 25: 1-17.
Wyckoff, P.H. and J.S. Clark (2005). Tree growth prediction using size and exposed crown area. Can. J. For. Res. 35: 13-20.

Zeide, B. (1989). Accuracy of equations describing diameter growth. Can. J. For. Res. 19: 1,283-1,286.

Zhang, L. (1997). Cross-validation of non-linear growth functions for modelling tree height-diameter relationships. Ann. Bot. 79: 251-257.

\section{Supplementary Materials}

The following supplementary materials for this article are presented on the following pages:

- Table S1. Growth form, maximum height, and diameter size range for the subset of the National Vegetation Survey data of New Zealand tree species used in this study.

- Table S2. Maximum-likelihood estimates and 2-unit support limits for parameters of the temperature-standardized growth-diameter power function scaling relationship for woody species of New Zealand forests, with species' growth form.

- Figure S1. The parameter trade-off between the coefficient ( $\beta$, given $\alpha$ ) and exponent $(\alpha)$ of the growth-diameter scaling relationship, $G(D)=\beta D^{\alpha}$, fit to data from 56 New Zealand tree species.

- Figure S2. Examples of parameter trade-offs between the exponent $(\alpha)$ and coefficient $(\beta)$ of the growth-diameter scaling relationship, $G(D)=\beta D^{\alpha}$ 
Electronic Appendix

\section{Covariation between $\alpha$ and $\beta$}

Based on all stems, significant negative covariation was observed between MLEs of $\alpha$ and $\beta$ for the 56 species (Spearman rank correlation; $\rho=-0.94 ; p<0.001 ;$ Fig. S1). The observed correlation could have resulted statistically because different combinations of $\alpha$ and $\beta$ can yield similar growth curves (Fig. S2). This issue was explored a posteriori by randomizing the species name associated with each pair of diameter-growth values, while preserving the distribution of species' abundances, and then re-estimating the MLEs of $\alpha$ and $\beta$ for each new 'species'. We performed 20 such randomizations and found that the MLEs of $\alpha$ and $\beta$ were strongly and significantly negatively correlated in all randomised data sets (mean Spearman rank correlation $\rho=-0.98$; $p<0.001$; Fig. S1), indicating that the observed covariation between $\alpha$ and $\beta$ did indeed result from a statistical parameter trade-off. However, this result does not imply that species have similar growth curves (Fig. 4): the AICs of the randomised datasets (obtained by summing AICs across all species for each randomisation) were substantially greater than that of the observed dataset $(\triangle \mathrm{AIC}=7425.0$ on average for the 20 randomisations $)$, confirming that true species differed greatly in their growth curves and that there was a substantial increase in explanatory power gained by accounting for true species identities. Variation among species in their growth curves was manifested as deviations of the MLEs of $\alpha$ and $\beta$ away from the restricted cluster of values generated by the randomizations (Fig. S1): the observed dataset had a significantly weaker correlation, based on comparison of the 
observed coefficient with the upper $95 \%$ confidence limit based on the 20 randomised datasets (Spearman rank correlation, $\rho_{\text {observed }}=-0.94$ vs $\rho_{\mathrm{CI}}=-0.96--0.99$ ). 
Table S1. Growth form (CT, canopy tree; ST, small tree; SH, shrub), maximum height $(\mathrm{Ht}(\mathrm{m}))$, and diameter size range $(\mathrm{mm})$ for the subset of the National Vegetation Survey data of New Zealand tree species used in this study.

Species (Family)

Beilschmiedia tawa (Lauraceae)

Dacrydium cupressinum (Podocarpaceae)

Dysoxylum spectabile (Meliaceae)

Griselinia littoralis (Cornaceae)

Hedycarya arborea (Monimiaceae)

Ixerba brexioides (Escalloniaceae)

Knightia excelsa (Proteaceae)

Kunzea ericoides (Myrtaceae)

Laurelia novae-zelandiae (Monimiaceae)

Litsea calicaris (Lauraceae)

Metrosideros umbellata (Myrtaceae)

Nothofagus fusca (Fagaceae)

Nothofagus menziesii (Fagaceae)

Nothofagus solandri (Fagaceae)

Nothofagus truncata (Fagaceae)

Podocarpus hallii (Podocarpaceae)

Prumnopitys ferruginea (Podocarpaceae)

Weinmannia racemosa (Cunoniaceae)

Brachyglottis repanda (Asteraceae)

Brachyglottis rotundifolia (Asteraceae)

Carpodetus serratus (Grossulariaceae)

Coprosma australis (Rubiaceae)

Coprosma linariifolia (Rubiaceae)

Dracophyllum traversii (Epacridaceae)

Elaeocarpus hookerianus (Elaeocarpaceae)

Fuchsia excorticata (Onagraceae)

Halocarpus biformis (Podocarpaceae)

Hoheria glabrata (Malvaceae)

Lepidothamnus intermedius (Podocarpaceae)

Leptospermum scoparium (Myrtaceae)

Melicytus ramiflorus (Violaceae)

Myrsine australis (Myrsinaceae)

Myrsine salicina (Myrsinaceae)

Pseudopanax colensoi (Araliaceae)

Olearia ilicifolia (Asteraceae)

Phyllocladus alpinus (Podocarpaceae)

\begin{tabular}{|c|c|c|}
\hline Growth form & $\mathrm{Ht}$ & Diameter range \\
\hline $\mathrm{CT}$ & 30 & $30-940$ \\
\hline $\mathrm{CT}$ & 50 & $30-1940$ \\
\hline $\mathrm{CT}$ & 17 & $30-631$ \\
\hline $\mathrm{CT}$ & 17 & $30-1110$ \\
\hline $\mathrm{CT}$ & 15 & $30-472$ \\
\hline $\mathrm{CT}$ & 17 & $33-574$ \\
\hline $\mathrm{CT}$ & 30 & $30-905$ \\
\hline $\mathrm{CT}$ & 16 & $30-740$ \\
\hline $\mathrm{CT}$ & 30 & $30-1511$ \\
\hline CT & 15 & $30-562$ \\
\hline $\mathrm{CT}$ & 20 & $30-2272$ \\
\hline $\mathrm{CT}$ & 35 & $30-2035$ \\
\hline $\mathrm{CT}$ & 30 & $30-1651$ \\
\hline CT & 27 & $30-1210$ \\
\hline $\mathrm{CT}$ & 30 & $30-1245$ \\
\hline CT & 20 & $30-1405$ \\
\hline $\mathrm{CT}$ & 35 & $30-905$ \\
\hline $\mathrm{CT}$ & 26 & $30-1738$ \\
\hline ST & 7 & $30-114$ \\
\hline $\mathrm{ST}$ & 10 & $43-372$ \\
\hline $\mathrm{ST}$ & 10 & $30-483$ \\
\hline $\mathrm{ST}$ & 7 & $30-207$ \\
\hline ST & 8 & $30-194$ \\
\hline ST & 10 & $30-467$ \\
\hline ST & 14 & $30-912$ \\
\hline ST & 13 & $34-650$ \\
\hline ST & 10 & $30-775$ \\
\hline $\mathrm{ST}$ & 10 & $35-524$ \\
\hline ST & 9 & $30-354$ \\
\hline ST & 8 & $30-489$ \\
\hline ST & 10 & $30-1380$ \\
\hline $\mathrm{ST}$ & 7 & $30-341$ \\
\hline $\mathrm{ST}$ & 10 & $30-380$ \\
\hline $\mathrm{ST}$ & 7 & $30-286$ \\
\hline ST & 7 & $30-475$ \\
\hline ST & 8 & $30-369$ \\
\hline
\end{tabular}




Pseudowintera axillaris (Winteraceae)
Pseudowintera colorata (Winteraceae)
Pseudopanax crassifolius (Araliaceae)
Pseudopanax linearis (Araliaceae)
Raukaua simplex (Araliaceae)
Quintinia acutifolia (Grossulariaceae)
Schefflera digitata (Araliaceae)
Archeria traversii (Epacridaceae)
Coprosma areolata (Rubiaceae)
Coprosma ciliata (Rubiaceae)
Coprosma foetidissima (Rubiaceae)
Coprosma parviflora (Rubiaceae)
Coprosma pseudociliata (Rubiaceae)
Coprosma tayloriae (Rubiaceae)
Cyathodes juniperina (Epacridaceae)
Dacrydium bidwillii (Podocarpaceae)
Dracophyllum longifolium (Epacridaceae)
Leucopogon fasciculatus (Epacridaceae)
Myrsine divaricata (Myrsinaceae)
Olearia colensoi (Asteraceae)

Pseudowintera axillaris (Winteraceae)

$\mathrm{SH}$

$\mathrm{SH}$

$\mathrm{SH}$

$\mathrm{SH}$

$\mathrm{SH}$

$\mathrm{SH}$

$\mathrm{SH}$

$\mathrm{SH}$

$\mathrm{SH}$

$\mathrm{SH}$

$\mathrm{SH}$

$\mathrm{SH}$

$\mathrm{SH}$
$30-170$

$30-230$

$30-351$

$30-137$

$30-338$

$30-392$

$32-202$

$30-415$

$30-249$

$30-140$

$30-307$

$30-98$

$30-137$

$30-164$

$30-134$

$30-374$

$30-315$

$30-148$

$30-215$

$30-277$ 
Table S2. Maximum-likelihood estimates (MLE) and 2-unit support limits (SL) for parameters of the temperature-standardized growth-diameter power function scaling relationship for woody species of New Zealand forests, with species' growth form (CT, canopy tree; ST, small tree; SH, shrub),. Note that " $\alpha \mid \beta$ " symbolizes that the SL or MLE for the parameter before the vertical line were estimated given the value of parameter after the vertical line fixed at its MLE, in this case $\alpha$ and $\beta$, respectively, as detailed in the Methods section of the main text.

Species (Family)

Beilschmiedia tawa (Lauraceae)

Dacrydium cupressinum (Podocarpaceae)

Dysoxylum spectabile (Meliaceae)

Griselinia littoralis (Cornaceae)

Hedycarya arborea (Monimiaceae)

Ixerba brexioides (Escalloniaceae)

Knightia excelsa (Proteaceae)

Kunzea ericoides (Myrtaceae)

Laurelia novae-zelandiae (Monimiaceae)

Litsea calicaris (Lauraceae)

Metrosideros umbellata (Myrtaceae)

Nothofagus fusca (Fagaceae)

Nothofagus menziesii (Fagaceae)

Nothofagus solandri (Fagaceae)

Nothofagus truncata (Fagaceae)

Podocarpus hallii (Podocarpaceae)

Prumnopitys ferruginea (Podocarpaceae)

Weinmannia racemosa (Cunoniaceae)

Brachyglottis repanda (Asteraceae)

\begin{tabular}{crcccccc}
\multicolumn{7}{c}{ All Stems } & \\
Growth & & MLE & Lower & Upper & MLE & Lower & Upper \\
form & $\mathrm{N}$ & $\alpha$ & SL $\alpha \mid \beta$ & SL $\alpha \mid \beta$ & $\beta \mid \alpha$ & SL $\beta \mid \alpha$ & SL $\beta \mid \alpha$ \\
CT & 800 & 0.69 & 0.670 & 0.708 & 0.038 & 0.0347 & 0.0413 \\
CT & 1937 & 0.32 & 0.306 & 0.332 & 0.133 & 0.1254 & 0.1410 \\
CT & 112 & 0.49 & 0.442 & 0.530 & 0.063 & 0.0521 & 0.0743 \\
CT & 3692 & 0.37 & 0.358 & 0.380 & 0.124 & 0.1173 & 0.1303 \\
CT & 823 & 0.33 & 0.312 & 0.346 & 0.233 & 0.2148 & 0.2511 \\
CT & 137 & 0.57 & 0.536 & 0.600 & 0.053 & 0.0444 & 0.0609 \\
CT & 354 & 0.85 & 0.828 & 0.870 & 0.022 & 0.0201 & 0.0244 \\
CT & 1309 & 0.53 & 0.504 & 0.554 & 0.055 & 0.0491 & 0.0612 \\
CT & 109 & 0.77 & 0.742 & 0.796 & 0.042 & 0.0373 & 0.0477 \\
CT & 253 & 0.89 & 0.862 & 0.914 & 0.020 & 0.0175 & 0.0221 \\
CT & 1815 & 0.21 & 0.188 & 0.230 & 0.228 & 0.2039 & 0.2514 \\
CT & 3593 & 0.59 & 0.582 & 0.598 & 0.069 & 0.0656 & 0.0715 \\
CT & 15775 & 0.55 & 0.544 & 0.556 & 0.051 & 0.0498 & 0.0529 \\
CT & 37390 & 0.43 & 0.428 & 0.432 & 0.133 & 0.1307 & 0.1346 \\
CT & 147 & 0.75 & 0.692 & 0.794 & 0.025 & 0.0190 & 0.0316 \\
CT & 2788 & -0.10 & -0.126 & -0.076 & 0.344 & 0.3089 & 0.3777 \\
CT & 816 & 0.38 & 0.352 & 0.404 & 0.116 & 0.1022 & 0.1307 \\
CT & 20532 & 0.56 & 0.556 & 0.564 & 0.047 & 0.0463 & 0.0483 \\
ST & 266 & $0.99 *$ & 0.910 & $0.998 *$ & 0.006 & 0.0047 & 0.0082
\end{tabular}


Table S2, continued

\begin{tabular}{|c|c|c|c|c|c|c|c|c|c|c|c|c|c|}
\hline \multicolumn{8}{|c|}{ Small Stems (3-20 cm diameter) } & \multicolumn{6}{|c|}{ Large Stems ( $\geq 20 \mathrm{~cm}$ diameter $)$} \\
\hline $\mathrm{N}$ & $\begin{array}{c}\text { MLE } \\
\alpha\end{array}$ & $\begin{array}{l}\text { Lower } \\
\text { SL } \alpha \mid \beta\end{array}$ & $\begin{array}{c}\text { Upper } \\
\text { SL } \alpha \mid \beta\end{array}$ & $\begin{array}{l}\text { MLE } \\
\beta \mid \alpha\end{array}$ & $\begin{array}{l}\text { Lower } \\
\text { SL } \beta \mid \alpha\end{array}$ & $\begin{array}{l}\text { Upper } \\
\text { SL } \beta \mid \alpha\end{array}$ & $\mathrm{N}$ & $\begin{array}{c}\text { MLE } \\
\alpha\end{array}$ & $\begin{array}{l}\text { Lower } \\
\text { SL } \alpha \mid \beta\end{array}$ & $\begin{array}{r}\text { Upper } \\
\text { SL } \alpha \mid \beta\end{array}$ & $\begin{array}{l}\text { MLE } \\
\beta \mid \alpha\end{array}$ & $\begin{array}{l}\text { Lower } \\
\text { SL } \beta \mid \alpha\end{array}$ & $\begin{array}{c}\text { Upper } \\
\text { SL } \beta \mid \alpha\end{array}$ \\
\hline 643 & 0.80 & 0.780 & 0.818 & 0.025 & 0.0231 & 0.0272 & 153 & -0.50 & -0.540 & -0.466 & 30 & 23.6 & 36.2 \\
\hline- & - & - & - & - & - & - & - & - & - & - & - & - & - \\
\hline 3134 & 0.31 & 0.298 & 0.322 & 0.160 & 0.1517 & 0.1690 & 555 & 0.29 & 0.256 & 0.318 & 0.217 & 0.1787 & 0.2547 \\
\hline 263 & 0.93 & 0.902 & 0.954 & 0.016 & 0.0143 & 0.0181 & - & - & - & - & - & - & - \\
\hline 1146 & 0.43 & 0.406 & 0.452 & 0.086 & 0.0776 & 0.0955 & 158 & 0.64 & 0.574 & 0.688 & 0.029 & 0.0203 & 0.0387 \\
\hline- & - & - & - & - & - & - & - & - & - & - & - & - & - \\
\hline 222 & $0.99 *$ & 0.964 & 0.998* & 0.014 & 0.0120 & 0.0151 & - & - & - & - & - & - & - \\
\hline 687 & 0.16 & 0.126 & 0.190 & 0.335 & 0.2876 & 0.3845 & 1125 & 0.21 & 0.178 & 0.238 & 0.166 & 0.1364 & 0.1952 \\
\hline- & - & - & - & - & - & - & - & - & - & - & - & - & - \\
\hline 1989 & -0.30 & -0.328 & -0.276 & 0.797 & 0.7147 & 0.8797 & 789 & -1.76 & -1.820 & -1.716 & 5092 & 3665.5 & 6539.5 \\
\hline 394 & 0.56 & 0.530 & 0.586 & 0.056 & 0.0489 & 0.0633 & 420 & -0.15 & -0.202 & -0.110 & 1.927 & 1.4226 & 2.4384 \\
\hline 16481 & 0.56 & 0.556 & 0.564 & 0.048 & 0.0466 & 0.0486 & 4020 & 0.02 & 0.006 & 0.034 & 0.994 & 0.9128 & 1.0774 \\
\hline 262 & $0.99 *$ & 0.914 & 0.998* & 0.007 & 0.0050 & 0.0084 & - & - & - & - & - & - & - \\
\hline
\end{tabular}


Table S2, continued.

\begin{tabular}{|c|c|c|c|c|c|c|c|c|}
\hline \multirow[b]{3}{*}{ Species (Family) } & \multicolumn{4}{|c|}{ All Stems } & \multirow{3}{*}{$\begin{array}{c}\text { Upper } \\
\text { SL } \alpha \mid \beta\end{array}$} & \multirow{3}{*}{$\begin{array}{l}\text { MLE } \\
\beta \mid \alpha\end{array}$} & \multirow{3}{*}{$\begin{array}{l}\text { Lower } \\
\text { SL } \beta \mid \alpha\end{array}$} & \multirow{3}{*}{$\begin{array}{c}\text { Upper } \\
\text { SL } \beta \mid \alpha\end{array}$} \\
\hline & Growth & & MLE & Lower & & & & \\
\hline & Form & $\mathrm{N}$ & $\alpha$ & $\operatorname{SL} \alpha \mid \beta$ & & & & \\
\hline Brachyglottis rotundifolia (Asteraceae) & ST & 107 & 0.55 & 0.490 & 0.596 & 0.110 & 0.0827 & 0.1371 \\
\hline Carpodetus serratus (Grossulariaceae) & ST & 1397 & 0.20 & 0.182 & 0.216 & 0.298 & 0.2757 & 0.3193 \\
\hline Coprosma australis (Rubiaceae) & ST & 316 & -0.02 & -0.076 & 0.026 & 0.638 & 0.5077 & 0.7714 \\
\hline Coprosma linariifolia (Rubiaceae) & ST & 693 & 0.14 & 0.118 & 0.160 & 0.335 & 0.3062 & 0.3646 \\
\hline Dracophyllum traversii (Epacridaceae) & $\mathrm{ST}$ & 208 & 0.04 & -0.012 & 0.084 & 0.298 & 0.2422 & 0.3555 \\
\hline Elaeocarpus hookerianus (Elaeocarpaceae) & $\mathrm{ST}$ & 218 & 0.32 & 0.248 & 0.376 & 0.083 & 0.0616 & 0.1043 \\
\hline Fuchsia excorticata (Onagraceae) & $\mathrm{ST}$ & 352 & 0.28 & 0.234 & 0.318 & 0.225 & 0.1817 & 0.2694 \\
\hline Halocarpus biformis (Podocarpaceae) & ST & 335 & 0.64 & 0.578 & 0.688 & 0.037 & 0.0280 & 0.0456 \\
\hline Hoheria glabrata (Malvaceae) & ST & 766 & 0.23 & 0.200 & 0.258 & 0.267 & 0.2314 & 0.3033 \\
\hline Lepidothamnus intermedius (Podocarpaceae) & ST & 189 & 0.20 & 0.164 & 0.232 & 0.120 & 0.1036 & 0.1364 \\
\hline Leptospermum scoparium (Myrtaceae) & ST & 420 & 0.02 & -0.006 & 0.044 & 0.835 & 0.7460 & 0.9262 \\
\hline Melicytus ramiflorus (Violaceae) & ST & 1885 & 0.10 & 0.082 & 0.116 & 0.359 & 0.3315 & 0.3869 \\
\hline Myrsine australis (Myrsinaceae) & ST & 502 & 0.64 & 0.616 & 0.660 & 0.031 & 0.0283 & 0.0344 \\
\hline Myrsine salicina (Myrsinaceae) & ST & 1563 & 0.12 & 0.100 & 0.138 & 0.277 & 0.2549 & 0.2999 \\
\hline Pseudopanax colensoi (Araliaceae) & ST & 131 & 0.10 & -0.014 & 0.180 & 0.275 & 0.1748 & 0.3789 \\
\hline Olearia ilicifolia (Asteraceae) & ST & 128 & -0.23 & -0.280 & -0.188 & 3.130 & 2.5534 & 3.7321 \\
\hline Phyllocladus alpinus (Podocarpaceae) & ST & 759 & 0.01 & -0.020 & 0.038 & 0.369 & 0.3258 & 0.4121 \\
\hline Pseudowintera axillaris (Winteraceae) & ST & 766 & -0.46 & -0.482 & -0.440 & 3.262 & 2.9971 & 3.5311 \\
\hline
\end{tabular}


Table S2, continued.

\begin{tabular}{|c|c|c|c|c|c|c|c|c|c|c|c|c|c|}
\hline \multicolumn{7}{|c|}{ Small Stems (3-20 cm diameter) } & \multicolumn{7}{|c|}{ Large Stems ( $\geq 20 \mathrm{~cm}$ diameter) } \\
\hline $\mathrm{N}$ & $\begin{array}{c}\text { MLE } \\
\alpha\end{array}$ & $\begin{array}{c}\text { Lower } \\
\text { SL } \alpha \mid \beta\end{array}$ & $\begin{array}{c}\text { Upper } \\
\text { SL } \alpha \mid \beta\end{array}$ & $\begin{array}{l}\text { MLE } \\
\beta \mid \alpha\end{array}$ & $\begin{array}{l}\text { Lower } \\
\text { SL } \beta \mid \alpha\end{array}$ & $\begin{array}{c}\text { Upper } \\
\text { SL } \beta \mid \alpha\end{array}$ & $\mathrm{N}$ & $\begin{array}{c}\text { MLE } \\
\alpha\end{array}$ & $\begin{array}{c}\text { Lower } \\
\text { SL } \alpha \mid \beta\end{array}$ & $\begin{array}{l}\text { Upper } \\
\text { SL } \alpha \mid \beta\end{array}$ & $\begin{array}{l}\text { MLE } \\
\beta \mid \alpha\end{array}$ & $\begin{array}{l}\text { Lower } \\
\text { SL } \beta \mid \alpha\end{array}$ & $\begin{array}{c}\text { Upper } \\
\text { SL } \beta \mid \alpha\end{array}$ \\
\hline- & - & - & - & - & - & - & - & - & - & - & - & - & - \\
\hline 1237 & 0.14 & 0.122 & 0.156 & 0.393 & 0.3634 & 0.4226 & 156 & -0.29 & -0.348 & -0.246 & 3.996 & 2.8772 & 5.1341 \\
\hline 312 & 0.20 & 0.158 & 0.236 & 0.261 & 0.2188 & 0.3031 & - & - & - & - & - & - & - \\
\hline 692 & 0.12 & 0.098 & 0.140 & 0.366 & 0.3346 & 0.3975 & - & - & - & - & - & - & - \\
\hline 192 & 0.05 & -0.004 & 0.094 & 0.288 & 0.2322 & 0.3443 & - & - & - & - & - & - & - \\
\hline 173 & 0.45 & 0.390 & 0.498 & 0.049 & 0.0378 & 0.0596 & - & - & - & - & - & - & - \\
\hline 253 & 0.40 & 0.348 & 0.442 & 0.134 & 0.1064 & 0.1627 & - & - & - & - & - & - & - \\
\hline 290 & 0.63 & 0.562 & 0.682 & 0.040 & 0.0299 & 0.0502 & - & - & - & - & - & - & - \\
\hline 669 & 0.32 & 0.290 & 0.346 & 0.179 & 0.1553 & 0.2027 & - & - & - & - & - & - & - \\
\hline 178 & 0.21 & 0.172 & 0.242 & 0.116 & 0.0994 & 0.1319 & - & - & - & - & - & - & - \\
\hline 388 & 0.00 & -0.026 & 0.024 & 0.909 & 0.8108 & 1.0098 & - & - & - & - & - & - & - \\
\hline 1572 & 0.07 & 0.052 & 0.086 & 0.410 & 0.3788 & 0.4412 & 119 & -1.52 & -1.590 & -1.470 & 3360 & 2298.1 & 4465.5 \\
\hline 480 & 0.70 & 0.678 & 0.720 & 0.025 & 0.0226 & 0.0273 & - & - & - & - & - & - & - \\
\hline 1515 & 0.10 & 0.082 & 0.118 & 0.304 & 0.2805 & 0.3277 & - & - & - & - & - & - & - \\
\hline 128 & -0.03 & -0.140 & 0.048 & 0.477 & 0.3092 & 0.6537 & - & - & - & - & - & - & - \\
\hline 104 & -0.29 & -0.346 & -0.244 & 4.006 & 3.1910 & 4.8655 & - & - & - & - & - & - & - \\
\hline 728 & -0.04 & -0.068 & -0.016 & 0.464 & 0.4146 & 0.5136 & - & - & - & - & - & - & - \\
\hline 765 & -0.43 & -0.450 & -0.412 & 2.920 & 2.6972 & 3.1462 & - & - & - & - & - & - & - \\
\hline
\end{tabular}


Table S2, continued.

Species (Family)

Pseudowintera colorata (Winteraceae)

Pseudopanax crassifolius (Araliaceae)

Pseudopanax linearis (Araliaceae)

Raukaua simplex (Araliaceae)

Quintinia acutifolia (Grossulariaceae)

Schefflera digitata (Araliaceae)

Archeria traversii (Epacridaceae)

Coprosma areolata (Rubiaceae)

Coprosma ciliata (Rubiaceae)

Coprosma foetidissima (Rubiaceae)

Coprosma parviflora (Rubiaceae)

Coprosma pseudociliata (Rubiaceae)

Coprosma tayloriae (Rubiaceae)

Cyathodes juniperina (Epacridaceae)

Dacrydium bidwillii (Podocarpaceae)

Dracophyllum longifolium (Epacridaceae)

Leucopogon fasciculatus (Epacridaceae)

Myrsine divaricata (Myrsinaceae)

Olearia colensoi (Asteraceae)
All Stems

$\begin{array}{crcccccc}\text { Growth } & & \text { MLE } & \text { Lower } & \text { Upper } & \text { MLE } & \text { Lower } & \text { Upper } \\ \text { Form } & \mathrm{N} & \alpha & \text { SL } \alpha \mid \beta & \text { SL } \alpha \mid \beta & \beta \mid \alpha & \text { SL } \beta \mid \alpha & \text { SL } \beta \mid \alpha \\ \text { ST } & 3520 & -0.16 & -0.170 & -0.150 & 1.029 & 0.9846 & 1.0742 \\ \text { ST } & 444 & 0.37 & 0.342 & 0.396 & 0.123 & 0.1085 & 0.1368 \\ \text { ST } & 181 & 0.08 & 0.026 & 0.126 & 0.215 & 0.1751 & 0.2562 \\ \text { ST } & 2063 & 0.10 & 0.086 & 0.112 & 0.366 & 0.3458 & 0.3868 \\ \text { ST } & 772 & 0.41 & 0.396 & 0.422 & 0.149 & 0.1404 & 0.1580 \\ \text { ST } & 207 & 0.23 & 0.164 & 0.282 & 0.275 & 0.2076 & 0.3437 \\ \text { SH } & 792 & -0.04 & -0.088 & 0.000 & 0.235 & 0.1934 & 0.2774 \\ \text { SH } & 111 & 0.06 & 0.026 & 0.090 & 1.382 & 1.1972 & 1.5713 \\ \text { SH } & 265 & 0.56 & 0.520 & 0.596 & 0.054 & 0.0457 & 0.0620 \\ \text { SH } & 2409 & 0.27 & 0.254 & 0.286 & 0.136 & 0.1272 & 0.1452 \\ \text { SH } & 109 & 0.96 & 0.842 & 0.998 * & 0.007 & 0.0045 & 0.0096 \\ \text { SH } & 338 & -1.61 & -1.720 & -1.528 & 67 & 44.6 & 90.7 \\ \text { SH } & 239 & 0.83 & 0.766 & 0.880 & 0.025 & 0.0197 & 0.0311 \\ \text { SH } & 222 & 0.35 & 0.288 & 0.400 & 0.067 & 0.0529 & 0.0813 \\ \text { SH } & 110 & -0.08 & -0.204 & 0.004 & 0.423 & 0.2610 & 0.5933 \\ \text { SH } & 402 & 0.26 & 0.224 & 0.292 & 0.109 & 0.0945 & 0.1243 \\ \text { SH } & 325 & -0.07 & -0.122 & -0.026 & 0.336 & 0.2751 & 0.3993 \\ \text { SH } & 1705 & 0.26 & 0.230 & 0.286 & 0.105 & 0.0938 & 0.1172 \\ \text { SH } & 207 & 0.06 & 0.010 & 0.102 & 0.350 & 0.2848 & 0.4181\end{array}$


Table S2, continued.

\begin{tabular}{|c|c|c|c|c|c|c|c|c|c|c|c|c|c|}
\hline \multicolumn{7}{|c|}{ Small Stems $(3-20 \mathrm{~cm}$ diameter $)$} & \multicolumn{7}{|c|}{ Large Stems ( $\geq 20 \mathrm{~cm}$ diameter $)$} \\
\hline $\mathrm{N}$ & $\begin{array}{c}\text { MLE } \\
\alpha\end{array}$ & $\begin{array}{l}\text { Lower } \\
\text { SL } \alpha \mid \beta\end{array}$ & $\begin{array}{c}\text { Upper } \\
\text { SL } \alpha \mid \beta\end{array}$ & $\begin{array}{l}\text { MLE } \\
\beta \mid \alpha\end{array}$ & $\begin{array}{l}\text { Lower } \\
\text { SL } \beta \mid \alpha\end{array}$ & $\begin{array}{c}\text { Upper } \\
\text { SL } \beta \mid \alpha\end{array}$ & $\mathrm{N}$ & $\begin{array}{c}\text { MLE } \\
\alpha\end{array}$ & $\begin{array}{c}\text { Lower } \\
\text { SL } \alpha \mid \beta\end{array}$ & $\begin{array}{l}\text { Upper } \\
\text { SL } \alpha \mid \beta\end{array}$ & $\begin{array}{l}\text { MLE } \\
\beta \mid \alpha\end{array}$ & $\begin{array}{l}\text { Lower } \\
\text { SL } \beta \mid \alpha\end{array}$ & $\begin{array}{l}\text { Upper } \\
\text { SL } \beta \mid \alpha\end{array}$ \\
\hline 3500 & -0.20 & -0.210 & -0.190 & 1.221 & 1.1701 & 1.2709 & - & - & - & - & - & - & - \\
\hline 180 & -0.10 & -0.152 & -0.056 & 0.432 & 0.3531 & 0.5123 & - & - & - & - & - & - & - \\
\hline 2029 & 0.13 & 0.118 & 0.142 & 0.325 & 0.3079 & 0.3418 & - & - & - & - & - & - & - \\
\hline 761 & -0.07 & -0.118 & -0.030 & 0.270 & 0.2224 & 0.3176 & - & - & - & - & - & - & - \\
\hline 109 & 0.07 & 0.036 & 0.100 & 1.328 & 1.1498 & 1.5116 & - & - & - & - & - & - & - \\
\hline 264 & 0.53 & 0.490 & 0.564 & 0.061 & 0.0518 & 0.0701 & - & - & - & - & - & - & - \\
\hline 2383 & 0.10 & 0.084 & 0.114 & 0.272 & 0.2553 & 0.2884 & - & - & - & - & - & - & - \\
\hline 107 & 0.76 & 0.670 & 0.826 & 0.016 & 0.0115 & 0.0208 & - & - & - & - & - & - & - \\
\hline 102 & 0.46 & 0.394 & 0.512 & 0.047 & 0.0360 & 0.0585 & - & - & - & - & - & - & - \\
\hline 392 & 0.21 & 0.176 & 0.240 & 0.137 & 0.1193 & 0.1555 & - & - & - & - & - & - & - \\
\hline 318 & -0.67 & -0.712 & -0.634 & 3.573 & 3.0534 & 4.1056 & - & - & - & - & - & - & - \\
\hline 1689 & 0.16 & 0.136 & 0.182 & 0.159 & 0.1444 & 0.1738 & - & - & - & - & - & - & - \\
\hline 197 & -0.12 & -0.170 & -0.076 & 0.744 & 0.6039 & 0.8898 & - & - & - & - & - & - & - \\
\hline
\end{tabular}

Notes: Species are listed alphabetically within growth forms. Parameters were estimated for species with a sample size (N) $\geq 100$ stems in each of three size classes: all stems, stems between $3-20 \mathrm{~cm}$ in diameter, and stems $\geq 20 \mathrm{~cm}$ in diameter. The scaling exponent $(\alpha)$ was systematically varied $(<0.99)$, and the values of $\beta$ and $s$ of the lognormal error distribution $($ given $\alpha)$ that minimized 
the negative log-likelihood were found. The 2-unit support limits represent the lower and upper values that are 2 log-likelihood units away from the minimum negative log-likelihood value. * denotes values that are at the search boundaries of parameters. See main text for details on methods for parameter-estimation. 
Figure S1. The parameter trade-off between the coefficient ( $\beta$, given $\alpha$ ) and exponent $(\alpha)$ of the growth-diameter scaling relationship, $\mathrm{G}(\mathrm{D})=\beta \mathrm{D}^{\alpha}$, fit to data from $56 \mathrm{New}$ Zealand tree species. For the larger symbols, each point represents one species' maximum likelihood estimate (MLE) using fits based on all stems. The symbols represent growth forms: squares, canopy trees; open circles, small trees; grey triangles, shrubs. Small crosses are MLEs based on data that has been randomized with respect to species identity (see Covariation between $\alpha$ and $\beta$ ). Note the logarithmic scale on the $\mathrm{x}$-axis.

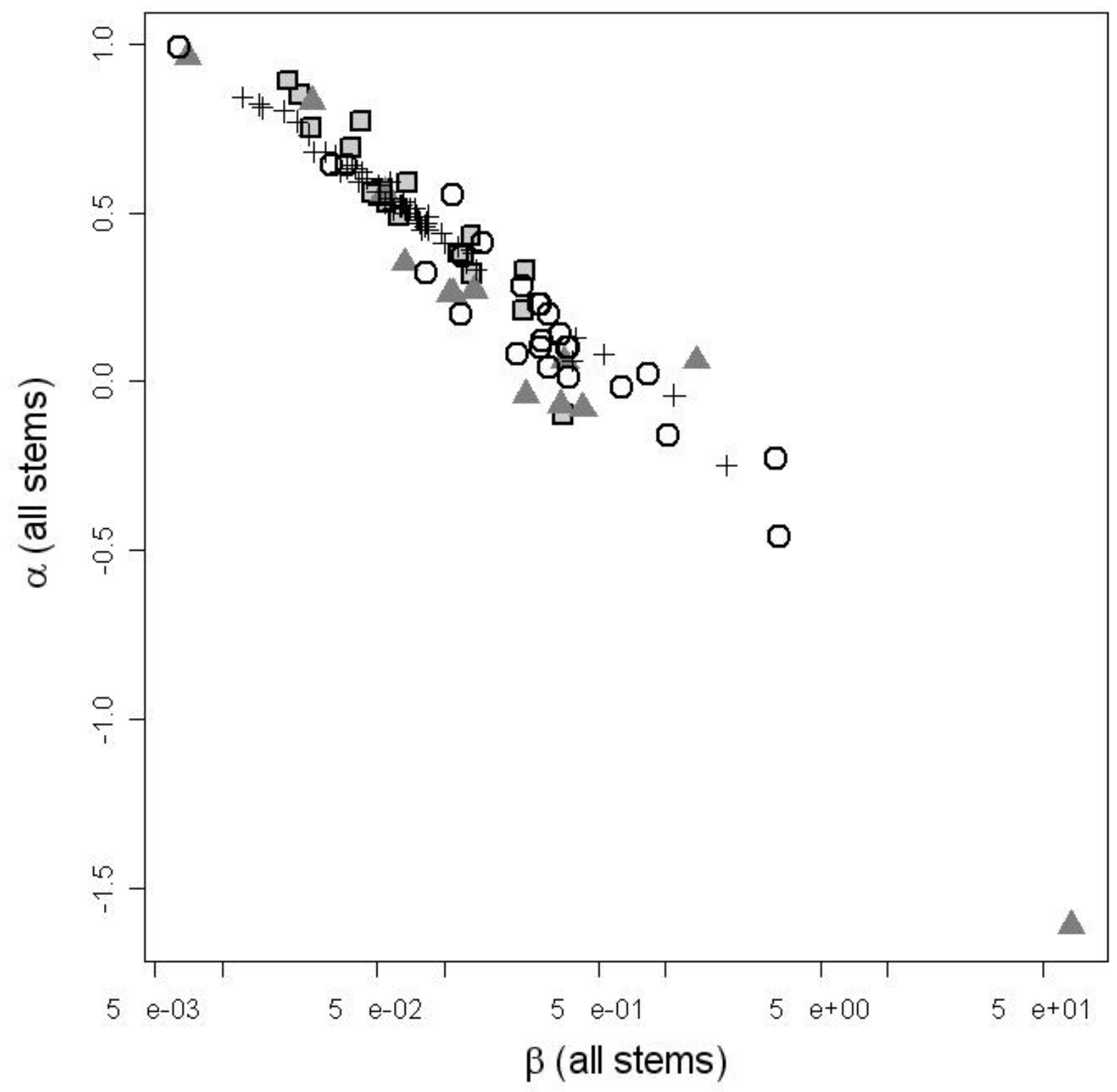


Figure S2. Examples of parameter trade-offs between the exponent $(\alpha)$ and coefficient $(\beta)$ of the growth-diameter scaling relationship, $G(D)=\beta D^{\alpha}$. Different combinations of $\alpha$ and $\beta$ can yield very similar tree diameter growth curves (compare A vs. B and C vs. D). Curves are not based on data.
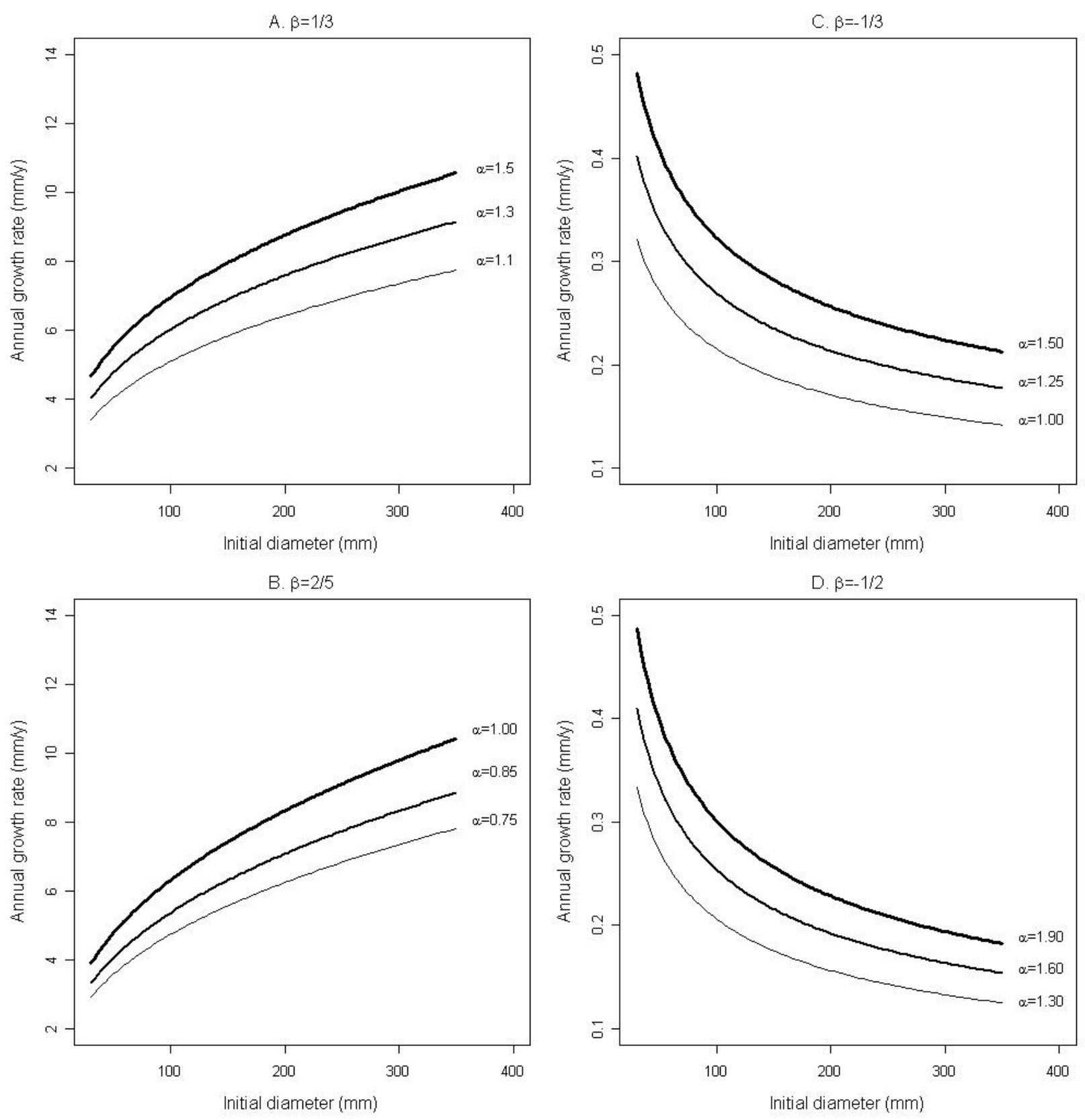